\title{
Heart valve isogeometric sequentially-coupled FSI analysis with the space-time topology change method
}

\author{
Takuya Terahara $^{1} \cdot$ Kenji Takizawa $^{1} \cdot$ Tayfun E. Tezduyar $^{2,3} \cdot$ Yuri Bazilevs $^{4} \cdot$ Ming-Chen Hsu $^{5}$
}

Received: 17 October 2019 / Accepted: 27 December 2019 / Published online: 10 January 2020

(c) The Author(s) 2020

\begin{abstract}
Heart valve fluid-structure interaction (FSI) analysis is one of the computationally challenging cases in cardiovascular fluid mechanics. The challenges include unsteady flow through a complex geometry, solid surfaces with large motion, and contact between the valve leaflets. We introduce here an isogeometric sequentially-coupled FSI (SCFSI) method that can address the challenges with an outcome of high-fidelity flow solutions. The SCFSI analysis enables dealing with the fluid and structure parts individually at different steps of the solutions sequence, and also enables using different methods or different mesh resolution levels at different steps. In the isogeometric SCFSI analysis here, the first step is a previously computed (fully) coupled Immersogeometric Analysis FSI of the heart valve with a reasonable flow solution. With the valve leaflet and arterial surface motion coming from that, we perform a new, higher-fidelity fluid mechanics computation with the space-time topology change method and isogeometric discretization. Both the immersogeometric and space-time methods are variational multiscale methods. The computation presented for a bioprosthetic heart valve demonstrates the power of the method introduced.
\end{abstract}

Keywords Bioprosthetic heart valve FSI analysis - Contact - Sequentially-coupled FSI - Immersogeometric analysis . Space-time topology change method $\cdot$ Space-time VMS method $\cdot$ Isogeometric discretization

\section{Introduction}

Kenji Takizawa

Kenji.Takizawa@tafsm.org

Tayfun E. Tezduyar

tezduyar@tafsm.org

Yuri Bazilevs

yuri_bazilevs@brown.edu

Ming-Chen Hsu

jmchsu@iastate.edu

1 Department of Modern Mechanical Engineering, Waseda University, 3-4-1 Ookubo, Shinjuku-ku, Tokyo 169-8555, Japan

2 Mechanical Engineering, Rice University - MS 321, 6100 Main Street, Houston, TX 77005, USA

3 Faculty of Science and Engineering, Waseda University, 3-4-1 Ookubo, Shinjuku-ku, Tokyo 169-8555, Japan

4 School of Engineering, Brown University, 184 Hope Street, Providence, RI 02912, USA

5 Department of Mechanical Engineering, Iowa State University, 2025 Black Engineering, Ames, IA 50011, USA

In addressing the computational challenges of heart valve fluid-structure interaction (FSI) analysis with high-fidelity flow solutions, in this article we introduce an isogeometric sequentially-coupled FSI (SCFSI) method. The SCFSI method (see [1-3] and references therein) enables dealing with the fluid and structure parts individually at different steps of the solutions sequence, and also enables using different methods or different mesh resolution levels at different steps. In the isogeometric SCFSI analysis here, the first step is a previously computed (fully) coupled Immersogeometric Analysis (IMGA) FSI of the heart valve from [4], which has a reasonable flow solution. With the valve leaflet and arterial surface motion coming from that, we perform a new, higher-fidelity fluid mechanics computation with a space-time (ST) computational method composed of core and special ST methods. The core component is the ST Variational Multiscale (ST-VMS) method [5-7], which subsumes its precursor "ST-SUPS" (see Sect. 1.4) and shares the residual-based VMS (RBVMS) [8-11] feature with the IMGA [4]. Beyond the ST-VMS, the key components are the ST Topology Change (ST-TC) method [12,13], which 
is used in combination with the ST Slip Interface (ST-SI) method [14,15], and the ST Isogeometric Analysis (ST-IGA) $[5,16,17]$. Integration of these components, resulting in the ST-SI-TC [18] and ST-SI-TC-IGA [19,20] methods, gives us the increased scope and accuracy we want in FSI analysis when there is contact between the moving solid surfaces or other TC. With the SCFSI method based on the IMGA and ST-SI-TC-IGA, we conduct an FSI analysis of a bioprosthetic heart valve (BHV).

\subsection{Moving-mesh and nonmoving-mesh methods}

Using the terminologies and categorizations used in [21-23], a method for flows with moving boundaries and interfaces (MBI) can be an interface-tracking (moving-mesh) method or an interface-capturing (nonmoving-mesh) method, or possibly a combination of the two. In a moving-mesh method, as the interface moves and the fluid mechanics domain changes its shape, the mesh moves to adjust to the shape change and to follow (i.e. "track") the interface.

Moving-mesh methods require mesh update methods. Mesh update typically consists of moving the mesh for as long as possible and remeshing as needed. With the key objectives being to maintain the element quality near solid surfaces and to minimize the frequency of remeshing, a number of advanced mesh update methods [24-28] were developed to be used with the ST-SUPS, including those that minimize the deformation of the layers of small elements placed near solid surfaces. Some of these methods have also been used with other moving-mesh methods. The advanced mesh update methods developed more recently [12,13,16,29-32] have been used mostly with the ST-VMS, and some of the methods are unique to the ST framework (see Sect. 1.8).

Moving the fluid mechanics mesh to follow a fluid-solid interface enables us to control the mesh resolution near the interface, have high-resolution representation of the boundary layers, and obtain accurate solutions in such critical flow regions. These desirable features do not come easily or do not come at all with the nonmoving-mesh methods. In these methods, the interface geometry is somehow represented over a nonmoving fluid mechanics mesh, with more accuracy in some methods than in some others, but the key point is that the fluid mechanics mesh does not move to follow the interface. Because the mesh is not following the interface, independent of how accurately the interface geometry is represented, the boundary layer resolution will be limited by the fluid mechanics mesh resolution where the interface is.

In many cases, finding the mesh update too challenging in an MBI problem is the reason for using a nonmoving-mesh method. Naturally, different researchers will have different thresholds for finding the mesh update too challenging. For some, even just a mesh moving without any remeshing could be too much. For some, the need for remeshing, no matter how small the associated cost is, could be too much. Some may find a near contact between solid surfaces or other near TC too much. Yet, some can bear it until the "end," giving up on the mesh update methods only when there is an actual contact or other TC, and even then, perhaps only partially. Some do not give up even then (see Sect. 1.6). What we need to keep in mind in all this is that, as pointed out in [33], "while it is understandable that fixed-mesh methods become more favored when the interface geometric complexity appears to be too high for a moving-mesh method, we need to remember that there is a difference between making the problem computable and obtaining good fluid mechanics accuracy near the interface."

As mentioned in [22], one of course recognizes that certain classes of interfaces (such as free-surface and twofluid flows with splashing) might be too complex to handle with an interface-tracking technique and, therefore, for all practical purposes, require an interface-capturing technique. The Mixed Interface-Tracking/Interface-Capturing Technique (MITICT) [27] was introduced in 2000 for computation of MBI problems that involve both fluid-solid interfaces that can be accurately tracked with a moving-mesh method and fluid-fluid interfaces that are too complex or unsteady to be tracked. Such fluid-fluid interfaces are captured over the mesh tracking the fluid-solid interfaces.

Thinking similarly about MBI problems with an actual contact or other TC, the Fluid-Solid Interface-Tracking/Interface-Capturing Technique (FSITICT) was introduced in 2009 [3] as the FSI version of the MITICT. In the FSITICT, we track the interface we can with a moving mesh, and capture over that moving mesh the interfaces we cannot track, specifically the interfaces where we need to have an actual contact between the solid surfaces.

\subsection{Computational challenges of heart valve FSI}

Heart valve FSI analysis is one of the computationally challenging cases in cardiovascular fluid mechanics. The challenges include unsteady flow through a complex geometry, solid surfaces with large motion, and contact between the valve leaflets. Because the flow has to be completely blocked at contact, this is a case of actual contact. The heart valve IMGA FSI analysis reported in [4] was with actual contact and was conducted in the framework of the FSITICT.

\subsection{SCFSI}

The SCFSI method was introduced [34,35] as an approximate FSI method in the context of arterial FSI, with the name Sequentially-Coupled Arterial FSI (SCAFSI). In the SCAFSI, first we compute a "reference" (i.e. "base") arterial deformation as a function of time, driven only by the blood 
pressure, which is given as a function of time by specifying the pressure profile in a cardiac cycle. Then we compute a sequence of updates involving mesh motion, fluid dynamics calculation, and recomputing the arterial deformation. In $[34,35]$ the method was in early stages of its development, the description was rather cursory, and the test computations were limited. A more extensive description of the method was provided in [1], together with a wider set of test computations.

Multiscale versions of the SCAFSI were introduced in [1], and the test computations were presented for the temporally multiscale version, using different time-step sizes for the structural and fluid mechanics parts. In the spatially multiscale versions proposed in [1], fluid mechanics meshes with different refinement levels are used at different stages of the FSI computation. We use a relatively coarse mesh at the early stages and reserve the highly-refined mesh for the stage where we plan to do the high-fidelity fluid mechanics computation. The spatially multiscale versions introduced in [1] included SCAFSI M1C. In that version, we first compute the time-dependent structure shape with the (fully) coupled FSI method and a relatively coarse fluid mechanics mesh, followed by mesh motion and fluid mechanics computation with a more refined mesh, obtaining a higher-fidelity fluid mechanics solution. Test computations with the spatially multiscale versions were first reported in a book chapter [36] and a conference paper [37], and then in journal articles $[2,3]$. The more general name "SCFSI" was introduced in [3,36,37], and SCFSI M2C was introduced in [3,37]. In SCFSI M2C, we first compute the time-dependent flow field with the (fully) coupled FSI method and a relatively coarse structural mechanics mesh, followed by a structural mechanics computation with a more refined mesh, obtaining a higher-fidelity structural mechanics solution.

\subsection{ST-VMS and ST-SUPS}

The Deforming-Spatial-Domain/Stabilized ST (DSD/SST) method $[28,38,39]$ was introduced for computation of flows with MBI, including FSI. In flow computations with MBI, the DSD/SST functions as a moving-mesh method, possessing the associated desirable features. Because the stabilization components of the original DSD/SST are the StreamlineUpwind/Petrov-Galerkin (SUPG) [40] and Pressure-Stabilizing/Petrov-Galerkin (PSPG) [38] stabilizations, it is now called "ST-SUPS." The ST-VMS [5-7] is the VMS version of the DSD/SST. It has two more stabilization terms beyond those in the ST-SUPS, and the additional terms give the method better turbulence modeling features. The ST-SUPS and ST-VMS, because of the higher-order accuracy of the ST framework (see $[5,6]$ ), are desirable also in computations without MBI.
As a moving-mesh method, the DSD/SST is an alternative to the Arbitrary Lagrangian-Eulerian (ALE) method, which is older (see, for example, [41]) and more commonly used. The ALE-VMS method [22,42-47] is the VMS version of the ALE. It succeeded the ST-SUPS and ALE-SUPS [48] and preceded the ST-VMS. To increase their scope and accuracy, the ALE-VMS and RBVMS are often supplemented with special methods, such as those for weakly-enforced Dirichlet boundary conditions [49-51] and "sliding interfaces" $[52,53]$. The ALE-SUPS, RBVMS and ALE-VMS have been applied to many classes of FSI, MBI and fluid mechanics problems. The classes of problems include ram-air parachute FSI [48], wind-turbine aerodynamics and FSI [54-64], more specifically, vertical-axis wind turbines [63-66], floating wind turbines [67], wind turbines in atmospheric boundary layers [62-64,68], and fatigue damage in wind-turbine blades [69], patient-specific cardiovascular fluid mechanics and FSI [42,70-75], biomedical-device FSI [4,76-80], ship hydrodynamics with free-surface flow and fluid-object interaction [81,82], hydrodynamics and FSI of a hydraulic arresting gear $[83,84]$, hydrodynamics of tidal-stream turbines with free-surface flow [85], passive-morphing FSI in turbomachinery [86], bioinspired FSI for marine propulsion [87,88], bridge aerodynamics and fluid-object interaction [89-91], and mixed ALE-VMS/IMGA computations $[4,79,80,92,93]$ in the framework of the FSITICT [3]. Recent advances in stabilized and multiscale methods may be found for stratified incompressible flows in [94], for divergence-conforming discretizations of incompressible flows in [95], and for compressible flows with emphasis on gas-turbine modeling in [96].

The ST-SUPS and ST-VMS have also been applied to many classes of FSI, MBI and fluid mechanics problems (see [97] for a comprehensive summary). The classes of problems include spacecraft parachute analysis for the landing-stage parachutes [22,31,98-100], cover-separation parachutes [101] and the drogue parachutes [102-104], wind-turbine aerodynamics for horizontal-axis wind-turbine rotors [22,23,54,105], full horizontal-axis wind-turbines $[30,60,106,107]$ and vertical-axis wind-turbines [14,63,64], flapping-wing aerodynamics for an actual locust [16,22, 29,108], bioinspired MAVs [106,107,109,110] and wingclapping [12,32], blood flow analysis of cerebral aneurysms [106,111], stent-blocked aneurysms [111-113], aortas [114118], heart valves $[12,13,19,20,107,116,118,119]$ and coronary arteries in motion [120], spacecraft aerodynamics $[101,121]$, thermo-fluid analysis of ground vehicles and their tires [7,119], thermo-fluid analysis of disk brakes [15], flow-driven string dynamics in turbomachinery [122-124], flow analysis of turbocharger turbines [17,125-128], flow around tires with road contact and deformation [18,119,129131], fluid films [131,132], ram-air parachutes [133], and 
compressible-flow spacecraft parachute aerodynamics [134, 135].

For completeness, we will include the ST-VMS in "Appendix A". The ST-SUPS, ALE-SUPS, RBVMS, ALE-VMS and ST-VMS all have some embedded stabilization parameters that play a significant role (see [22]). These parameters involve a measure of the local length scale (also known as "element length") and other parameters such as the element Reynolds and Courant numbers. There are many ways of defining the stabilization parameters. Some of the newer options for the stabilization parameters used with the SUPS and VMS can be found in [7,14,16,30,105,130,136-139]. Some of the earlier stabilization parameters used with the SUPS and VMS were also used in computations with other SUPG-like methods, such as the computations reported in [86,140-151]. We will specify in "Appendix B" which stabilization parameters we use in the computation reported in this article.

\subsection{ST-SI}

The ST-SI was introduced in [14], in the context of incompressible-flow equations, to retain the desirable moving-mesh features of the ST-VMS and ST-SUPS in computations involving spinning solid surfaces, such as a turbine rotor. The mesh covering the spinning surface spins with it, retaining the high-resolution representation of the boundary layers, while the mesh on the other side of the SI remains unaffected. This is accomplished by adding to the ST-VMS formulation interface terms similar to those in the version of the ALE-VMS for computations with sliding interfaces $[52,53]$. The interface terms account for the compatibility conditions for the velocity and stress at the SI, accurately connecting the two sides of the solution. An ST-SI version where the SI is between fluid and solid domains was also presented in [14]. The SI in that case is a "fluid-solid SI" rather than a standard "fluid-fluid SI" and enables weak enforcement of the Dirichlet boundary conditions for the fluid. The ST-SI introduced in [15] for the coupled incompressible-flow and thermal-transport equations retains the high-resolution representation of the thermo-fluid boundary layers near spinning solid surfaces. These ST-SI methods have been applied to aerodynamic analysis of vertical-axis wind turbines [14,63,64], thermo-fluid analysis of disk brakes [15], flow-driven string dynamics in turbomachinery [122-124], flow analysis of turbocharger turbines [17,125-128], flow around tires with road contact and deformation [18,119,129-131], fluid films [131,132], aerodynamic analysis of ram-air parachutes [133], and flow analysis of heart valves [19,20,116,118].

In the ST-SI version presented in [14] the SI is between a thin porous structure and the fluid on its two sides. This enables dealing with the porosity in a fashion consistent with how the standard fluid-fluid SIs are dealt with and how the
Dirichlet conditions are enforced weakly with fluid-solid SIs. This version also enables handling thin structures that have T-junctions. This method has been applied to incompressibleflow aerodynamic analysis of ram-air parachutes with fabric porosity [133]. The compressible-flow ST-SI methods were introduced in [134], including the version where the SI is between a thin porous structure and the fluid on its two sides. Compressible-flow porosity models were also introduced in [134]. These, together with the compressible-flow ST SUPG method [152], extended the ST computational analysis range to compressible-flow aerodynamics of parachutes with fabric and geometric porosities. That enabled ST computational flow analysis of the Orion spacecraft drogue parachute in the compressible-flow regime [134,135].

For completeness, we will include the ST-SI in "Appendix A". The interface terms in the ST-SI also involve element length, in the direction normal to the interface. We will specify in "Appendix B" which element length we use for that in the computation reported in this article.

\subsection{ST-TC}

The ST-TC $[12,13]$ was introduced for moving-mesh computation of flow problems with TC, such as contact between solid surfaces. Even before the ST-TC, the ST-SUPS and STVMS, when used with robust mesh update methods, have proven effective in flow computations where the solid surfaces are in near contact or create other near TC, if the nearness is sufficiently near for the purpose of solving the problem. Many classes of problems can be solved that way with sufficient accuracy. For examples of such computations, see the references mentioned in [12]. The ST-TC made moving-mesh computations possible even when there is an actual contact between solid surfaces or other TC. By collapsing elements as needed, without changing the connectivity of the "parent" mesh, the ST-TC can handle an actual TC while maintaining high-resolution boundary layer representation near solid surfaces. This enabled successful moving-mesh computation of heart valve flows [12,13,19,20,107,116,118,119], wing clapping [12,32], flow around a rotating tire with road contact and prescribed deformation [18,119,129-131], and fluid films [131,132].

\subsection{ST-SI-TC}

The ST-SI-TC is the integration of the ST-SI and ST-TC. A fluid-fluid SI requires elements on both sides of the SI. When part of an SI needs to coincide with a solid surface, which happens for example when the solid surfaces on two sides of an SI come into contact or when an SI reaches a solid surface, the elements between the coinciding SI part and the solid surface need to collapse with the ST-TC mechanism. The collapse switches the SI from fluid-fluid SI to fluid- 
solid SI. With that, an SI can be a mixture of fluid-fluid and fluid-solid SIs. With the ST-SI-TC, the elements collapse and are reborn independent of the nodes representing a solid surface. The ST-SI-TC enables high-resolution flow representation even when parts of the SI are coinciding with a solid surface. It also enables dealing with contact location change and contact sliding. This was applied to heart valve flow analysis $[19,20,116,118]$, tire aerodynamics with road contact and deformation [18,119,129-131,131], and fluid films [131,132].

\subsection{ST-IGA}

The success with IGA basis functions in space [42,52,70,153] motivated the integration of the ST methods with isogeometric discretization, which we broadly call "ST-IGA." The ST-IGA was introduced in [5]. Computations with the STVMS and ST-IGA were first reported in [5] in a 2D context, with IGA basis functions in space for flow past an airfoil, and in both space and time for the advection equation. Using higher-order basis functions in time enables deriving full benefit from using higher-order basis functions in space. This was demonstrated with the stability and accuracy analysis given in [5] for the advection equation.

The ST-IGA with IGA basis functions in time enables a more accurate representation of the motion of the solid surfaces and a mesh motion consistent with that. This was pointed out in $[5,6]$ and demonstrated in $[16,29,109]$. It also enables more efficient temporal representation of the motion and deformation of the volume meshes, and more efficient remeshing. These motivated the development of the ST/NURBS Mesh Update Method (STNMUM) $[16,29,109]$, with the name coined in [30]. The STNMUM has a wide scope that includes spinning solid surfaces. With the spinning motion represented by quadratic NURBS in time, and with sufficient number of temporal patches for a full rotation, the circular paths are represented exactly. A "secondary mapping" $[5,6,16,22]$ enables also specifying a constant angular velocity for invariant speeds along the circular paths. The ST framework and NURBS in time also enable, with the "ST-C" method, extracting a continuous representation from the computed data and, in large-scale computations, efficient data compression $[7,15,119,122-$ 124,154]. The STNMUM and the ST-IGA with IGA basis functions in time have been used in many 3D computations. The classes of problems solved are flapping-wing aerodynamics for an actual locust $[16,22,29,108]$, bioinspired MAVs [106,107,109,110] and wing-clapping [12,32], separation aerodynamics of spacecraft [101], aerodynamics of horizontal-axis $[30,60,106,107]$ and vertical-axis $[14,63,64]$ wind-turbines, thermo-fluid analysis of ground vehicles and their tires [7,119], thermo-fluid analysis of disk brakes [15], flow-driven string dynamics in turbomachinery [122-124], flow analysis of turbocharger turbines [17,125-128], and flow analysis of coronary arteries in motion [120].

The ST-IGA with IGA basis functions in space enables more accurate representation of the geometry and increased accuracy in the flow solution. It accomplishes that with fewer control points, and consequently with larger effective element sizes. That in turn enables using larger time-step sizes while keeping the Courant number at a desirable level for good accuracy. It has been used in ST computational flow analysis of turbocharger turbines [17,125-128], flow-driven string dynamics in turbomachinery [123,124], ram-air parachutes [133], spacecraft parachutes [135], aortas [116-118], heart valves [19,20,116,118], coronary arteries in motion [120], tires with road contact and deformation [129131], and fluid films [131,132]. Using IGA basis functions in space is now a key part of some of the newest arterial zerostress-state estimation methods [118,155-160] and related shell analysis [161].

\subsection{ST-SI-IGA and ST-SI-TC-IGA}

The ST-SI-IGA is the integration of the ST-SI and ST-IGA, and the ST-SI-TC-IGA is the integration of the ST-SI, ST-TC and ST-IGA.

The turbocharger turbine flow [17,125-128] and flowdriven string dynamics in turbomachinery $[123,124]$ were computed with the ST-SI-IGA. The IGA basis functions were used in the spatial discretization of the fluid mechanics equations and also in the temporal representation of the rotor and spinning-mesh motion. That enabled accurate representation of the turbine geometry and rotor motion and increased accuracy in the flow solution. The IGA basis functions were used also in the spatial discretization of the string structural dynamics equations. That enabled increased accuracy in the structural dynamics solution, as well as smoothness in the string shape and fluid dynamics forces computed on the string.

The ram-air parachute analysis [133] and spacecraft parachute compressible-flow analysis [135] were conducted with the ST-SI-IGA, based on the ST-SI version that weakly enforces the Dirichlet conditions and the ST-SI version that accounts for the porosity of a thin structure. The ST-IGA with IGA basis functions in space enabled, with relatively few number of unknowns, accurate representation of the parafoil and parachute geometries and increased accuracy in the flow solution. The volume mesh needed to be generated both inside and outside the parafoil. Mesh generation inside was challenging near the trailing edge because of the narrowing space. The spacecraft parachute has a very complex geometry, including gores and gaps. Using IGA basis functions addressed those challenges and still kept the element density near the trailing edge of the parafoil and around the spacecraft parachute at a reasonable level. 
The heart valve flow analysis $[19,20,116,118]$ was conducted with the ST-SI-TC-IGA. The method, beyond enabling a more accurate representation of the geometry and increased accuracy in the flow solution, kept the element density in the narrow spaces near the contact areas at a reasonable level. When solid surfaces come into contact, the elements between the surface and the SI collapse. Before the elements collapse, the boundaries could be curved and rather complex, and the narrow spaces might have high-aspect-ratio elements. With NURBS elements, it was possible to deal with such adverse conditions rather effectively.

In computational analysis of flow around tires with road contact and deformation [130,131], the ST-SI-TC-IGA enables a more accurate representation of the geometry and motion of the tire surfaces, a mesh motion consistent with that, and increased accuracy in the flow solution. It also keeps the element density in the tire grooves and in the narrow spaces near the contact areas at a reasonable level. In addition, we benefit from the mesh generation flexibility provided by using SIs.

In computational analysis of fluid films [131,132], the ST-SI-TC-IGA enables solution with a computational cost comparable to that of the Reynolds-equation model for the comparable solution quality [132]. With that, narrow gaps associated with the road roughness [131] can be accounted for in the flow analysis around tires.

An SI provides mesh generation flexibility in a general context by accurately connecting the two sides of the solution computed over nonmatching meshes. This type of mesh generation flexibility is especially valuable in complex-geometry flow computations with isogeometric discretization, removing the matching requirement between the NURBS patches without loss of accuracy. This feature was used in the flow analysis of heart valves [19,20,116,118], turbocharger turbines [17,125-128], and spacecraft parachute compressibleflow analysis [135].

\subsection{Outline of the remaining sections}

In Sect. 2, we present the SCFSI analysis of the BHV. The concluding remarks are given in Sect. 3. The ST-VMS and ST-SI are given in "Appendix A", and the stabilization parameters in "Appendix B".

\section{SCFSI analysis of a BHV}

In the SCFSI analysis, the first step is a (fully) coupled IMGA FSI computation [4] of the BHV, with a cardiac cycle of $T=0.86 \mathrm{~s}$. The computation was driven by a prescribed left-ventricular pressure at the inlet and a resistance boundary condition at the outlet, and the corresponding flow rate was obtained as part of the FSI solution. With the BHV and



Fig. 1 BHV model. Leaflets, metal frame, and sinuses

arterial-surface motion coming from the FSI solution, we perform a new fluid mechanics computation with the ST-SITC-IGA.

\subsection{Geometry}

The model, shown in Fig. 1, has three leaflets and a metal frame. In the IMGA FSI computation [4], the BHV is represented with cubic T-splines, and the arterial surface with quadratic NURBS. Figure 2 shows the BHV and arterialsurface meshes.

\subsection{Surface mesh in the ST-SI-TC-IGA computation}

The structure model is of zero thickness in geometry. Even in the closed position of the valve, there are small gaps between the model surfaces, including the metal surfaces. However, the flow solver, because of the way the IMGA deals with zero-thickness geometries, in combination with the limited mesh refinement, could see the gaps as closed. In our case, we want the flow solver to see the model surfaces accurately so that the moving-mesh method can do what it is good at - enable high-resolution flow representation near those surfaces. Our method for closing the gaps is to add just enough thickness to the surface geometries coming from the IMGA computation. We select the thickness to be small so that our 

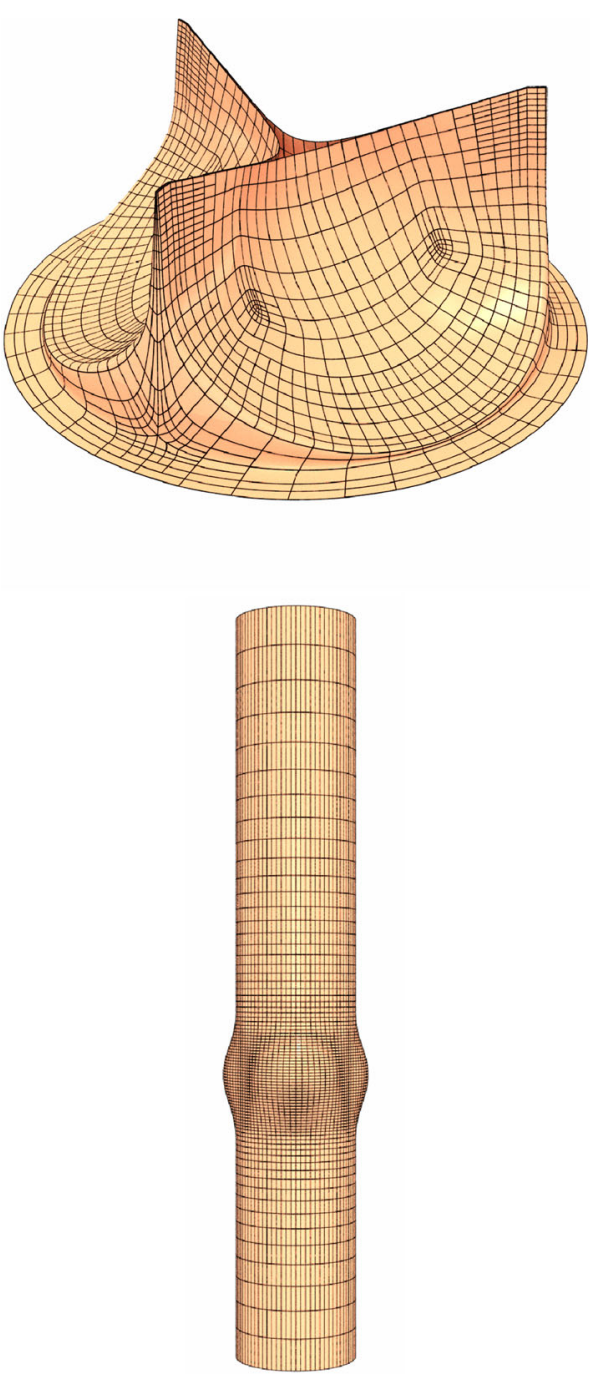

Fig. 2 BHV mesh with cubic T-spline elements and arterial-surface mesh with quadratic NURBS elements in the IMGA FSI computation [4]

model geometry is as close to the IMGA geometry as possible. It is roughly 10 times smaller than the structure thickness used in the IMGA computation. We start with a thickness of $4.921 \times 10^{-3} \mathrm{~cm}$, determined based on closing the gaps between the metal surfaces, which are not deforming. That being our maximum thickness, we reduce it locally to prevent overlap between the model surfaces, but only when we need to do so during the cardiac cycle, in a time-varying fashion.

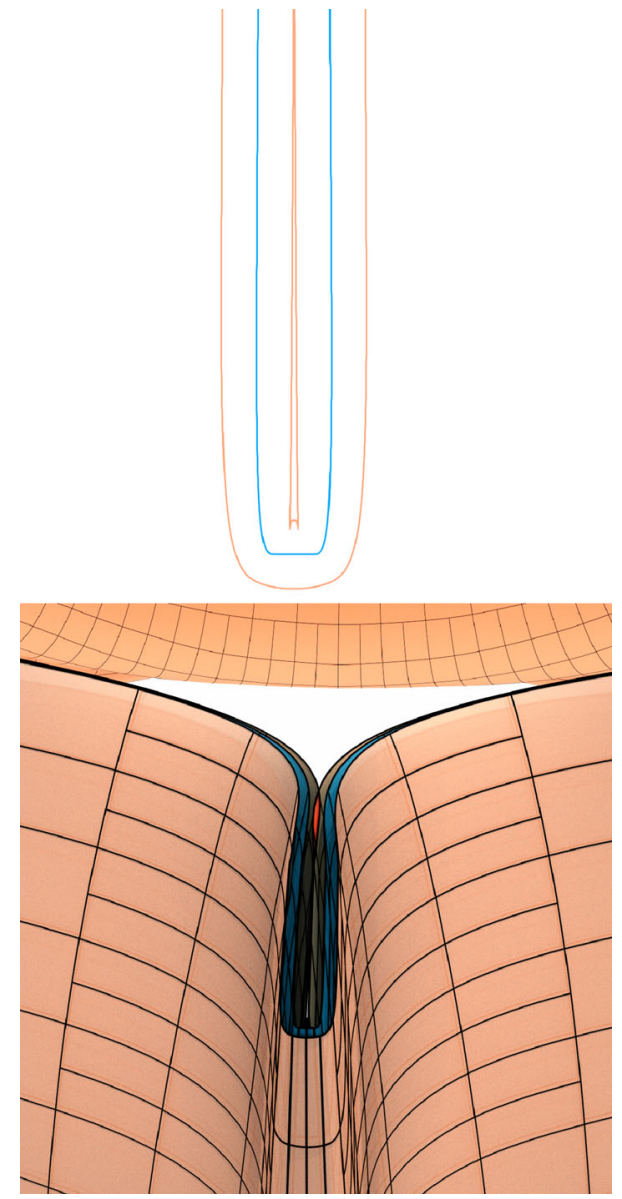

Fig. 3 Original surface (blue) and the surfaces giving the structure thickness (orange). 2D view of the free edge (top) and 3D close-up view from where the leaflets connect to the metal frame (bottom). (Color figure online)

Figure 3 shows the surfaces added on the two sides, giving the structure thickness. We project the surfaces created on the two sides to quadratic-NURBS representation, and then connect the surfaces with a rounding arch. The rounding arch and the surfaces are connected in a tangent form. With the rounding, as an added benefit, we can capture the small-scale flow patterns near the free edges of the leaflets. The structural displacements from the IMGA computation are projected to the original surface and that is applied to the corresponding points of the surfaces on the two sides. Figures 4 and 5 show the valve surfaces. Figure 6 shows the artery quadratic NURBS surfaces. 

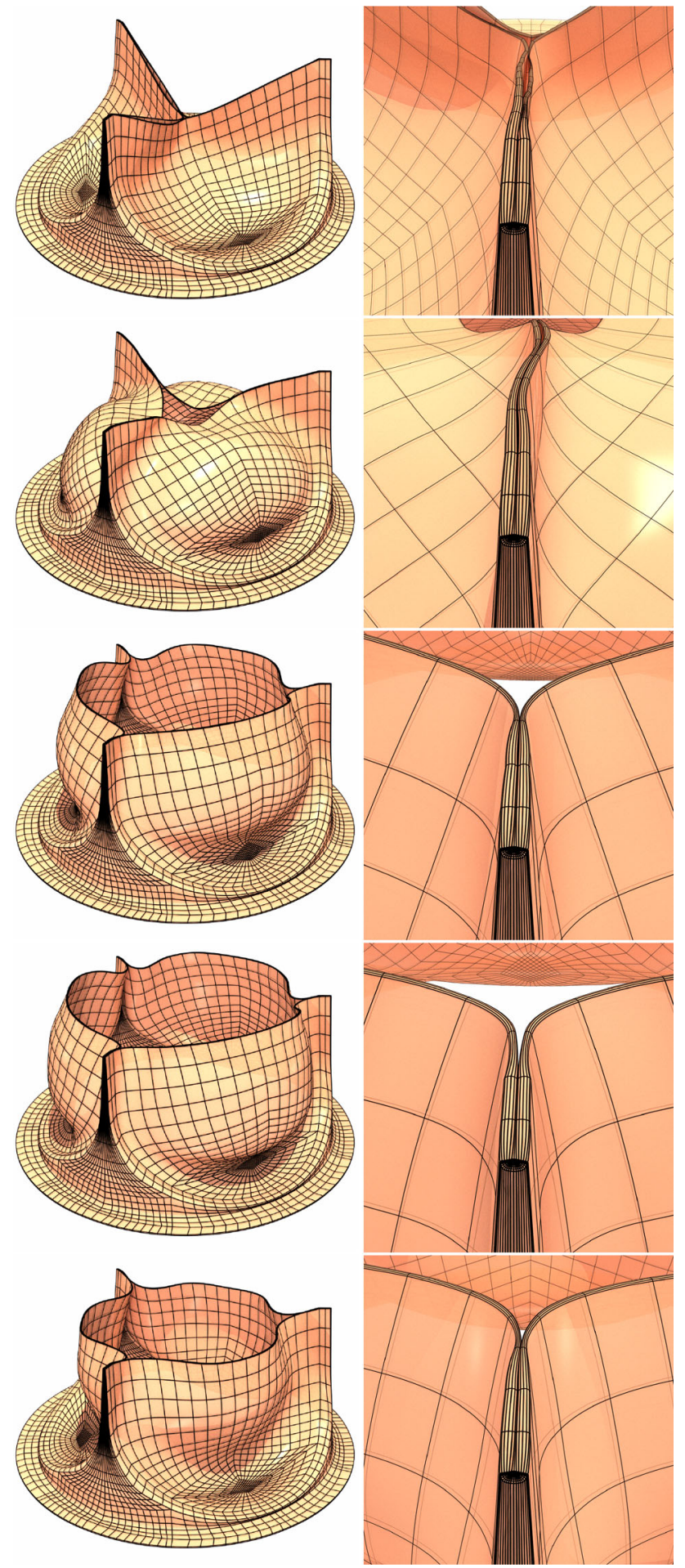

Fig. 4 Valve quadratic NURBS surfaces with the rounding arch, full view (left) and close-up view from where the leaflets connect to the metal frame (right). The frames are for $t=0.175,0.275,0.315,0.495$, $0.585 \mathrm{~s}$
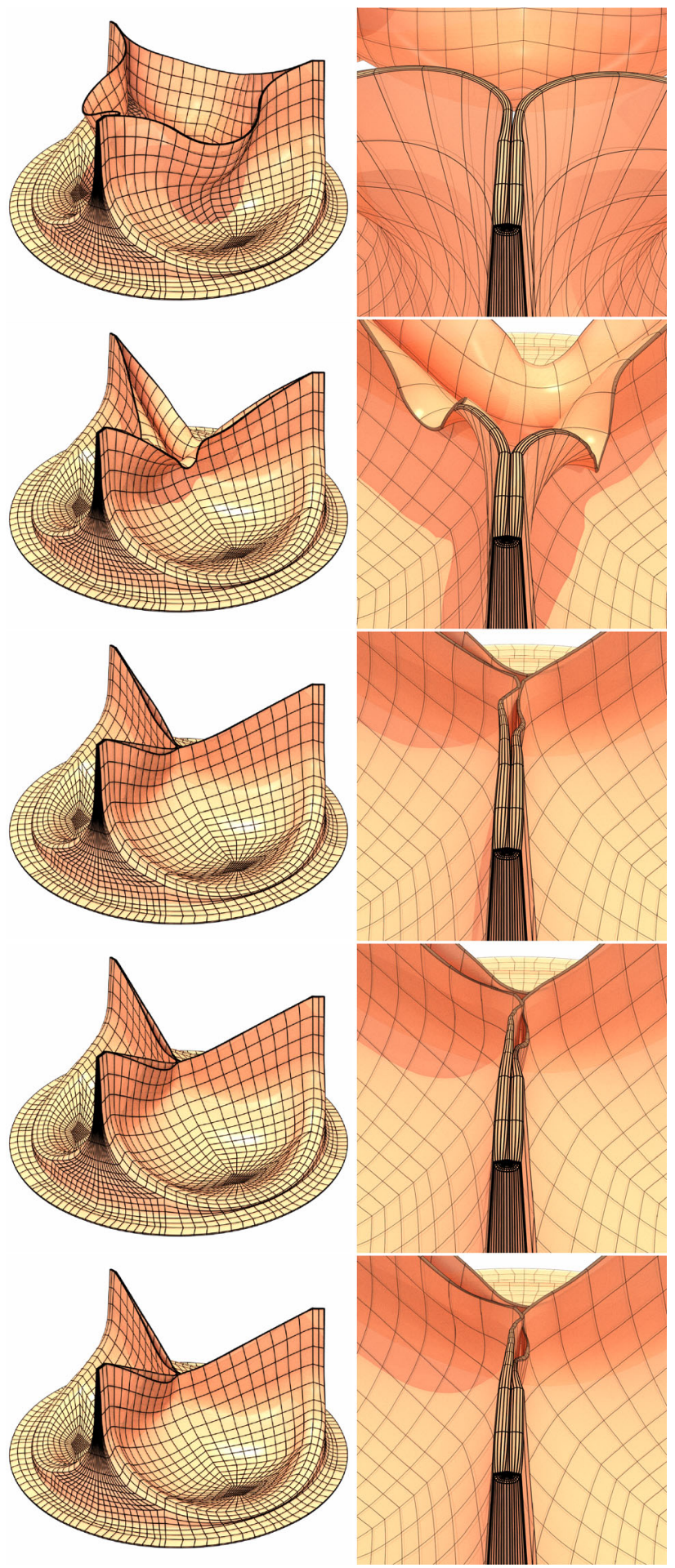

Fig. 5 Valve quadratic NURBS surfaces with the rounding arch, full view (left) and close-up view from where the leaflets connect to the metal frame (right). The frames are for $t=0.590,0.595,0.605,0.635$, $0.785 \mathrm{~s}$ 

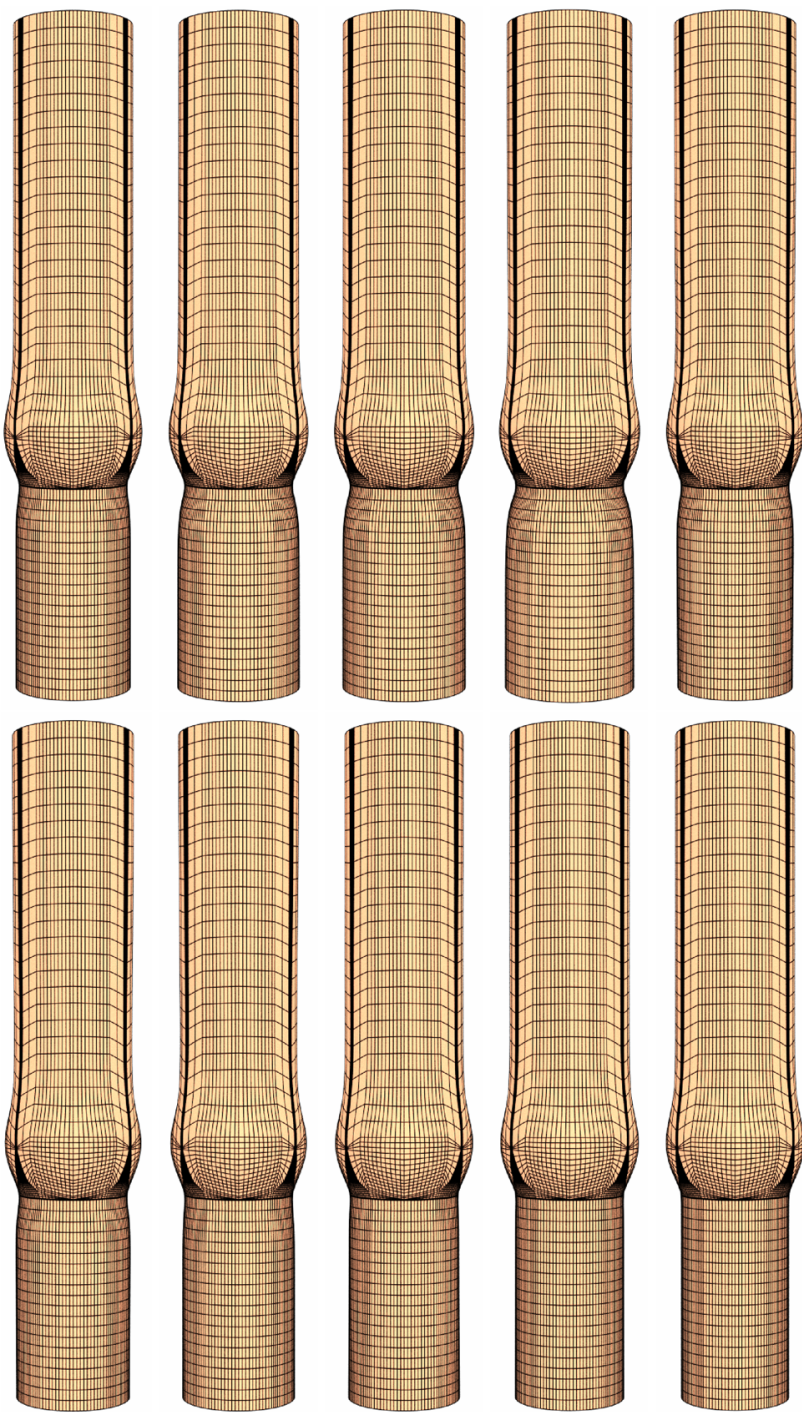

Fig. 6 Artery quadratic NURBS surfaces. The frames are for $t=0.175$, $0.275,0.315,0.495,0.585,0.590,0.595,0.605,0.635,0.785 \mathrm{~s}$

\subsection{Mesh and inflow conditions}

We create a template mesh with three SIs. The mesh has three parts, identified as Part 1, Part 2 and Part 3. Figure 7 shows the three SIs and the three parts of the mesh. The number of control points and number of elements are 429,780 and 289,452. Part 1 faces the SIs and will have the elements that will collapse and become reborn by the motion of the leaflets. Part 2 remains unchanged during the computation. Part 3 is the mesh between Part 1, Part 2 and the arterial wall. The motion of Part 1, following the leaflet motion, is
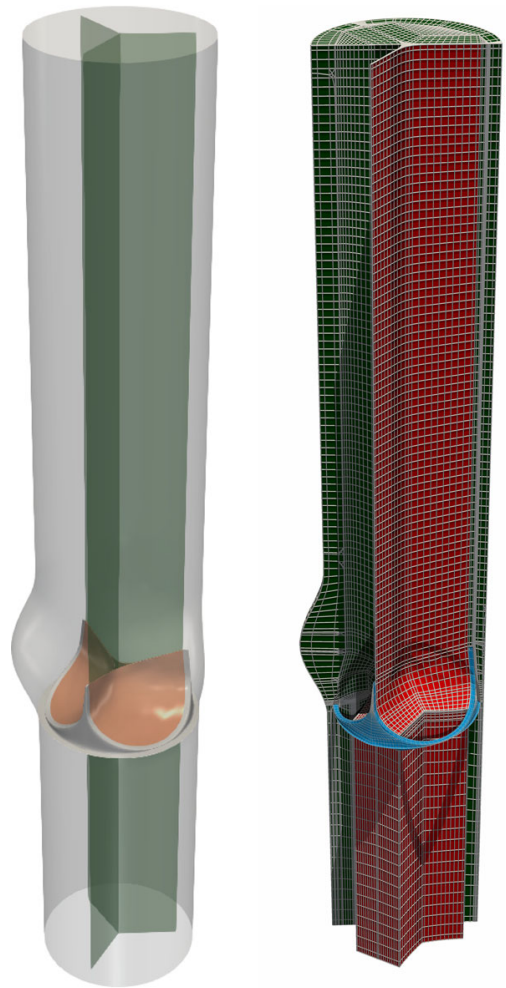

Fig. 7 The three SIs of the template mesh (left) and the three parts of the mesh (right): Part 1 (red), Part 2 (blue), and half of Part 3 (green). (Color figure online)

generated with a method taking into account the contact. The motion of Part 3 is generated automatically, by solving the steady-state structural mechanics equations based on the neoHookean model with Jacobian-based stiffening [7,22,24-26, 162], following Part 1, the leaflet motion and the artery wall motion. Figures 8 and 9 show the mesh motion.

The boundary conditions are no-slip on the valve and the arterial wall, traction-free at the outflow boundary, and uniform velocity at the inflow boundary. We use the flow rate from the IMGA computation. When the valve is closed, the flow rate at the inflow boundary and the time derivative of the closed-space volume do not match. Figure 10 shows that discrepancy. We note that the volume we are time-differentiating is the volume of the mesh zone that covers the closed space, which we will call "time-differentiation volume." In dealing with the discrepancy, in the closed-valve time periods, we set the flow rate equal to the time derivative of the closed-space volume. In narrow time zones neighboring the closed-valve periods, we set the flow rate equal to a value blended between 


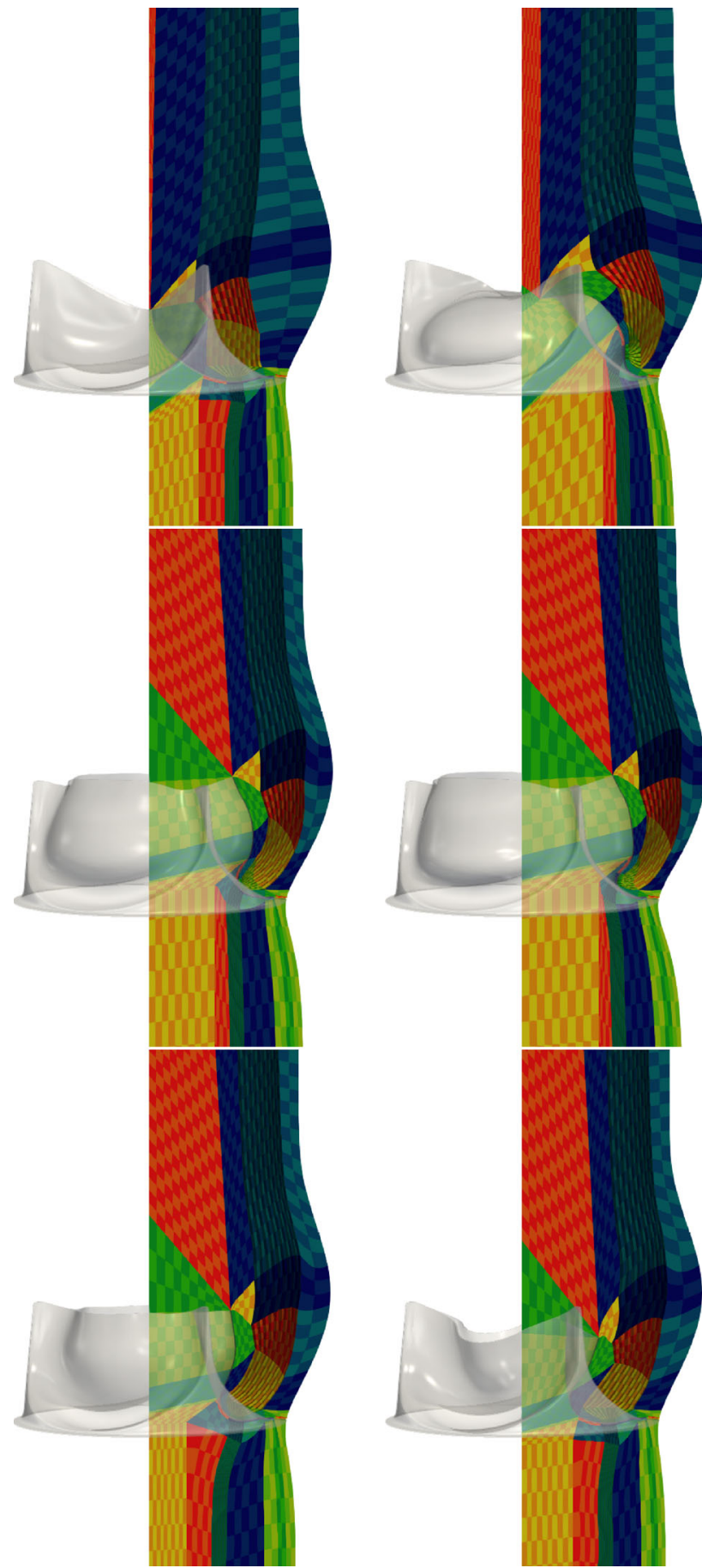

Fig. 8 Cross-section of the volume mesh at $t=0.175,0.275,0.315$, $0.495,0.585,0.590 \mathrm{~s}$. The checkerboard coloring is for differentiating between the NURBS elements. (Color figure online)
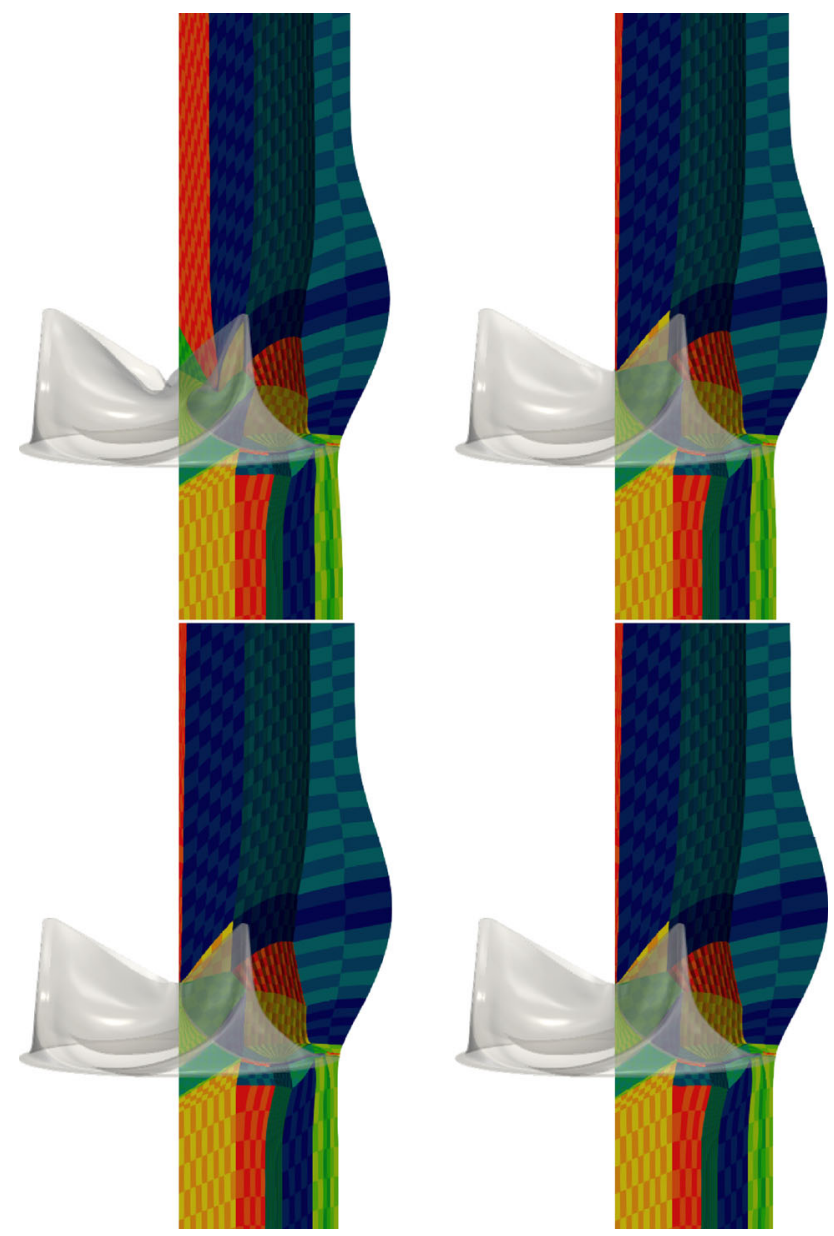

Fig. 9 Cross-section of the volume mesh at $t=0.595,0.605,0.635$, $0.785 \mathrm{~s}$. The checkerboard coloring is for differentiating between the NURBS elements. (Color figure online)

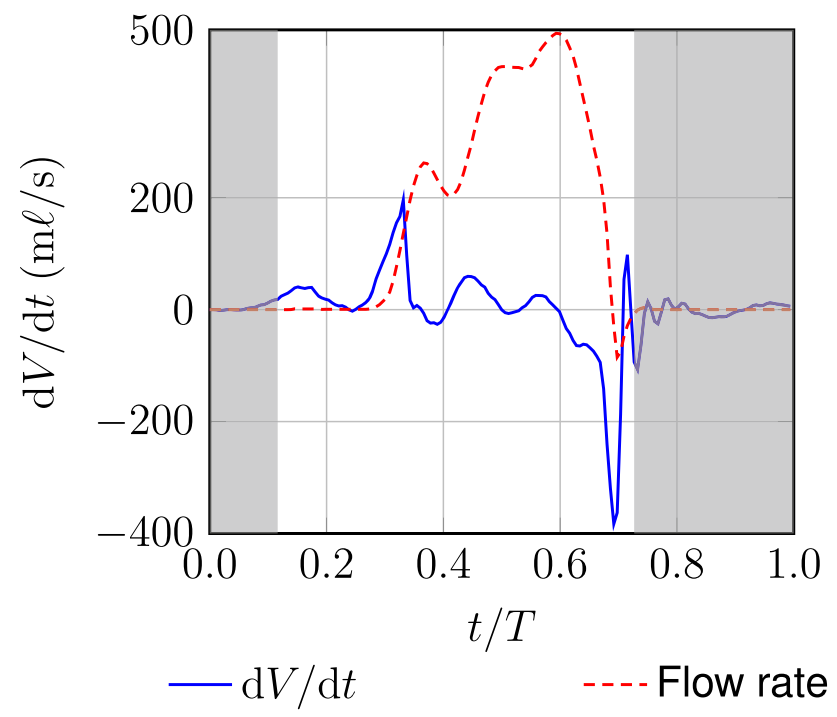

Fig. 10 Flow rate and time derivative of the closed-space volume. The gray time zone is when the valve is closed. The volume that we are time-differentiating is the volume of the mesh zone that covers the closed space 


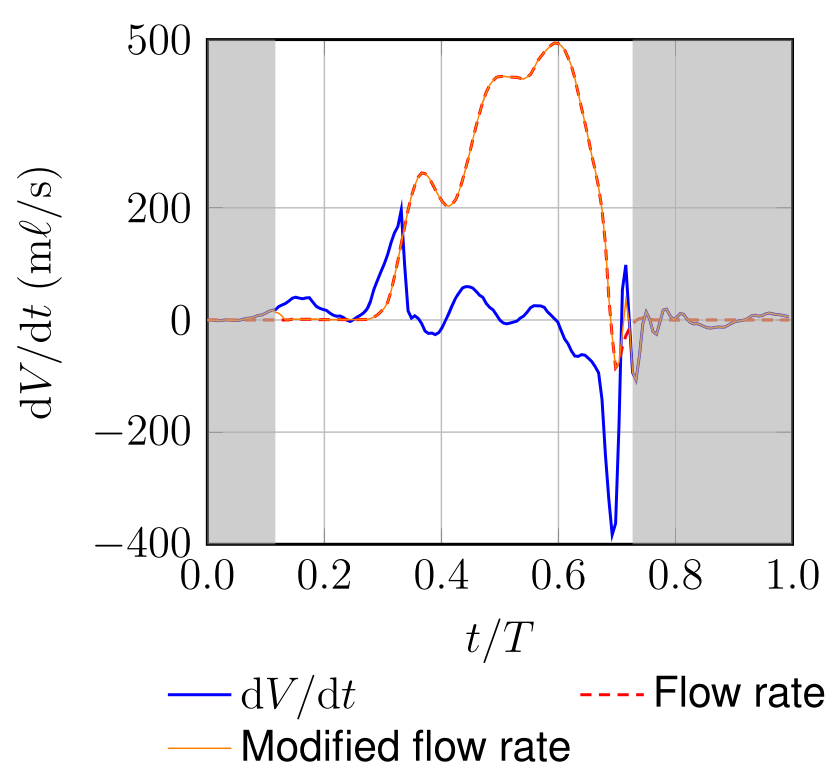

Fig. 11 Flow rate, time derivative of the closed-space volume, and the modified flow rate. The gray time zone is when the valve is closed. The volume that we are time-differentiating is the volume of the mesh zone that covers the closed space

the actual flow rate and the time derivative of the timedifferentiation volume.

Figure 11 shows the modified flow rate. Figure 12 shows the inflow velocity corresponding to the modified flow rate.

\subsection{Computational conditions}

We use the ST-SUPS (see "Appendix A", which contains also the ST-SI), with the stabilization parameters given in "Appendix B". The time-step size is $5.00 \times 10^{-3} \mathrm{~s}$. The number of nonlinear iterations per time step is 3 , and the number of GMRES iterations per nonlinear iteration is 300 .

\subsection{Results}

Figures 13 and 14 show the flow patterns from the second cardiac cycle. The figures demonstrate that we are able to capture

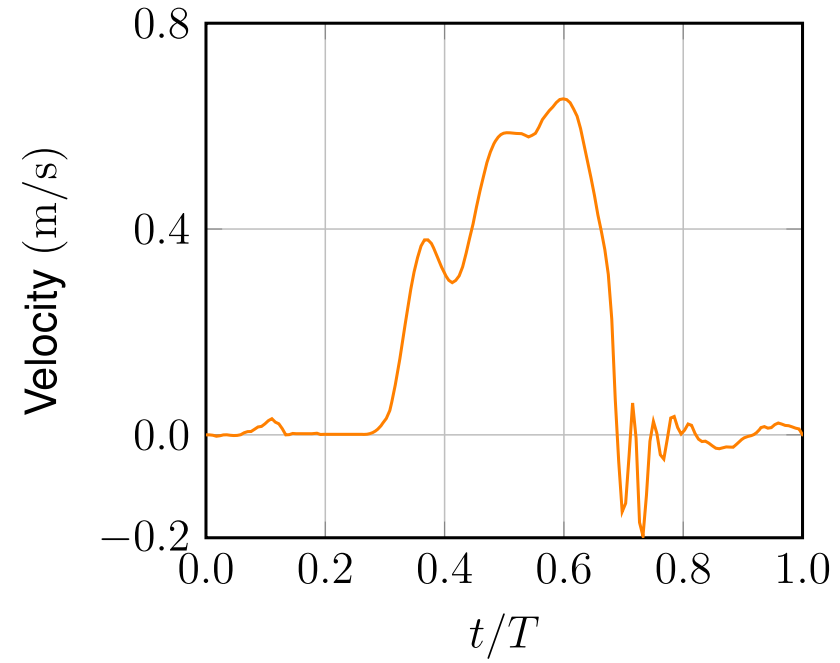

Fig. 12 Inflow velocity

the sheet-like flow structure emanating from the leaflet edges and we have a reasonable flow field even when the leaflet surfaces come into contact. Figure 15 shows the corresponding wall shear stress (WSS) on the valve surfaces. The WSS is high around the leaflet edges and on the upstream-side of the leaflet surfaces.

\section{Concluding remarks}

We have introduced an isogeometric SCFSI method that can address some of the toughest computational challenges of heart valve FSI analysis with high-fidelity flow solutions. Beyond the challenges related to the unsteady flow through a complex geometry and the solid surfaces with large motion, we have addressed the challenges related to the contact between the valve leaflets with a SCFSI combination of immersogeometric and ST computational methods. Both the immersogeometric and ST methods are variational multiscale methods. Because the ST computational method is a moving-mesh method, it enables high-resolution representa- 


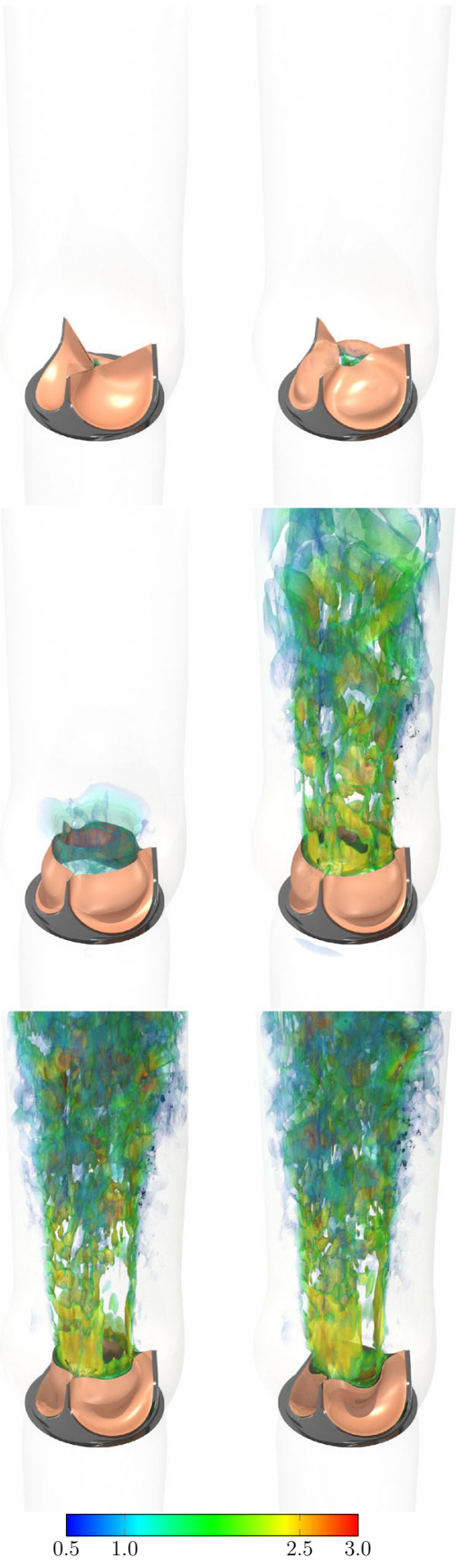

Fig. 13 Isosurfaces corresponding to a positive value of the second invariant of the velocity gradient tensor, colored by the velocity magnitude $(\mathrm{m} / \mathrm{s})$. The frames are for $t=1.035,1.135,1.175,1.355,1.445$, $1.450 \mathrm{~s}$

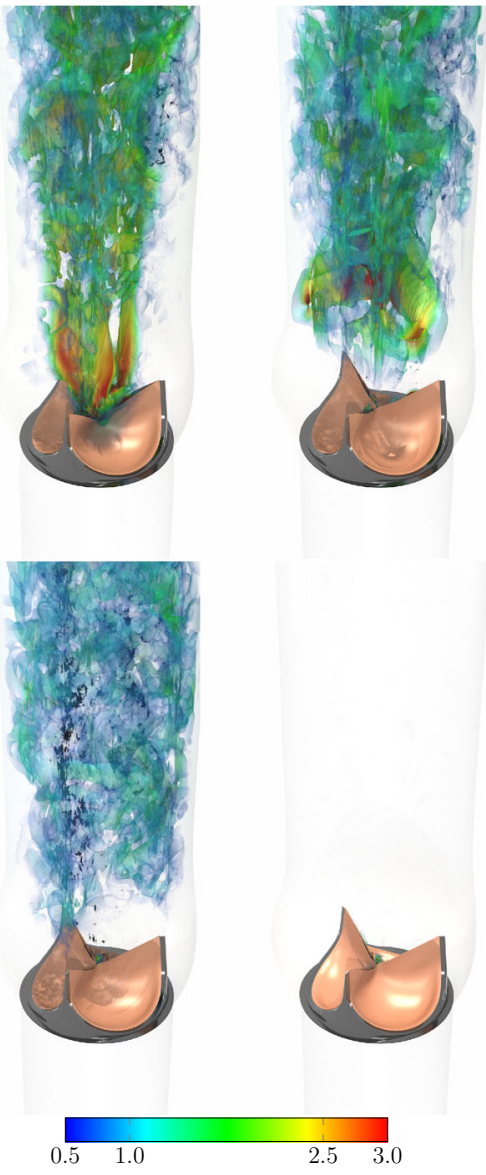

Fig. 14 Isosurfaces corresponding to a positive value of the second invariant of the velocity gradient tensor, colored by the velocity magnitude $(\mathrm{m} / \mathrm{s})$. The frames are for $t=1.455,1.465,1.495,1.645 \mathrm{~s}$

tion of the boundary layers near moving solid surfaces. The SCFSI analysis enables dealing with the fluid and structure parts individually at different steps of the solutions sequence, and also enables using different methods or different mesh resolution levels at different steps. In the isogeometric SCFSI analysis we presented here, the first step was a previously computed (fully) coupled IMGA FSI of the heart valve with a reasonable flow solution. Taking the valve leaflet and arterial surface motion coming from that, we performed a higher-fidelity fluid mechanics computation with the ST-SITC-IGA. With the computation presented for a BHV, we demonstrated the power of the method introduced. 

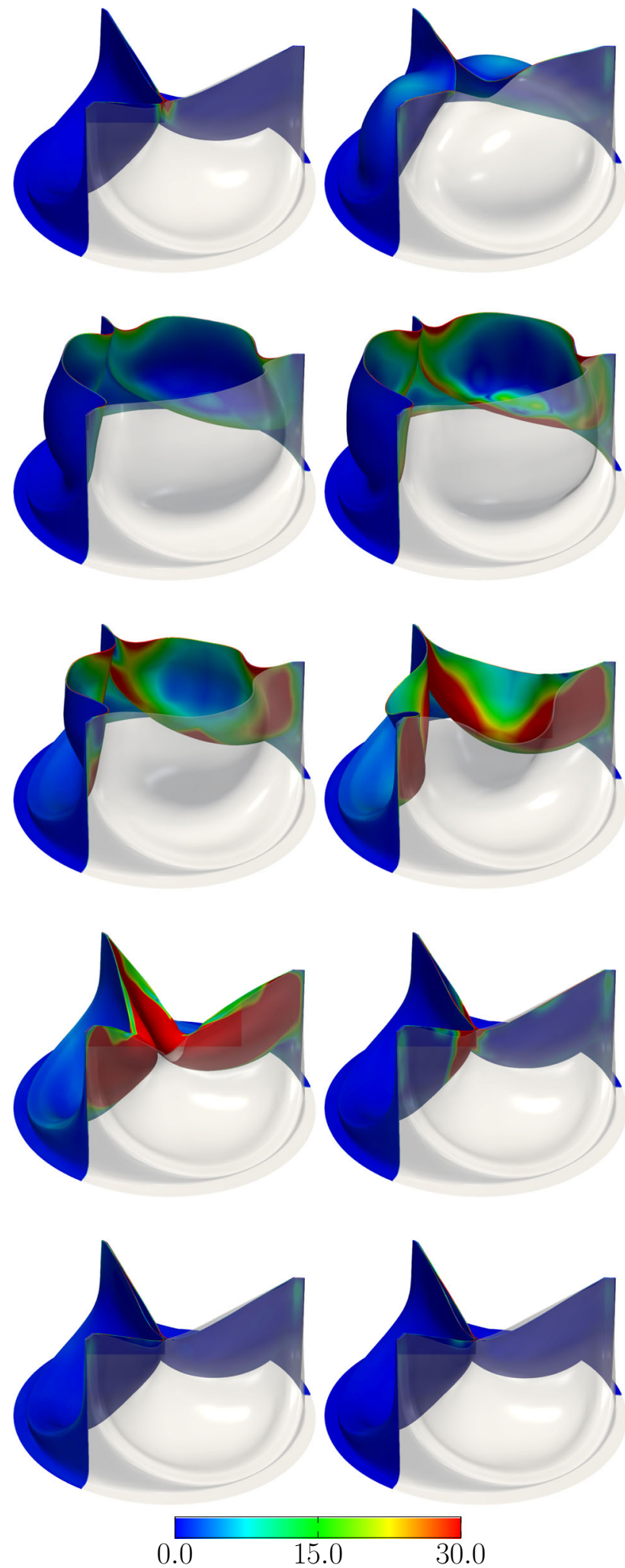

Fig. 15 Magnitude of the WSS (Pa). One-third of the valve is transparent. The frames are for $t=1.035,1.135,1.175,1.355,1.445,1.450$, $1.455,1.465,1.495,1.645 \mathrm{~s}$
Acknowledgements This work was supported (first and second authors) in part by JST-CREST; Grant-in-Aid for Scientific Research (A) 18H04100 from Japan Society for the Promotion of Science; and RiceWaseda research agreement. This work was also supported (first author) in part by Grant-in-Aid for JSPS Research Fellow 17J11096. The mathematical model and computational method parts of the work were also supported (third author) in part by ARO Grant W911NF-17-1-0046, ARO DURIP Grant W911NF-18-1-0234, and Top Global University Project of Waseda University. The fourth author was partially supported by NSF Grant 1854436, and the fifth author was partially supported by NIH/NHLBI Grants R01HL129077 and R01HL142504. The authors acknowledge the Texas Advanced Computing Center (TACC) at The University of Texas at Austin for providing HPC resources that have contributed to the research results reported within this paper.

Open Access This article is licensed under a Creative Commons Attribution 4.0 International License, which permits use, sharing, adaptation, distribution and reproduction in any medium or format, as long as you give appropriate credit to the original author(s) and the source, provide a link to the Creative Commons licence, and indicate if changes were made. The images or other third party material in this article are included in the article's Creative Commons licence, unless indicated otherwise in a credit line to the material. If material is not included in the article's Creative Commons licence and your intended use is not permitted by statutory regulation or exceeds the permitted use, you will need to obtain permission directly from the copyright holder. To view a copy of this licence, visit http://creativecomm ons.org/licenses/by/4.0/.

\section{A ST-VMS and ST-SI}

For completeness, we include, mostly from [14,18], the STVMS and ST-SI methods.

\section{A.1 ST-VMS}

The ST-VMS is given as

$$
\begin{aligned}
& \int_{Q_{n}} \mathbf{w}^{h} \cdot \rho\left(\frac{\partial \mathbf{u}^{h}}{\partial t}+\mathbf{u}^{h} \cdot \nabla \mathbf{u}^{h}-\mathbf{f}^{h}\right) \mathrm{d} Q \\
&+\int_{Q_{n}} \boldsymbol{\varepsilon}\left(\mathbf{w}^{h}\right): \boldsymbol{\sigma}^{h} \mathrm{~d} Q-\int_{\left(P_{n}\right)_{\mathrm{h}}} \mathbf{w}^{h} \cdot \mathbf{h}^{h} \mathrm{~d} P \\
&+\int_{Q_{n}} q^{h} \boldsymbol{\nabla} \cdot \mathbf{u}^{h} \mathrm{~d} Q+\int_{\Omega_{n}}\left(\mathbf{w}^{h}\right)_{n}^{+} \cdot \rho\left(\left(\mathbf{u}^{h}\right)_{n}^{+}-\left(\mathbf{u}^{h}\right)_{n}^{-}\right) \mathrm{d} \Omega \\
&+\sum_{e=1}^{\left(n_{\mathrm{e} 1}\right)_{n}} \int_{Q_{n}^{e}} \frac{\tau_{\mathrm{SUPS}}}{\rho}\left(\rho\left(\frac{\partial \mathbf{w}^{h}}{\partial t}+\mathbf{u}^{h} \cdot \nabla \mathbf{w}^{h}\right)\right. \\
&+\sum_{e=1}^{\left(n_{\mathrm{el}}\right)_{n}} \int_{Q_{n}^{e}} \nu_{\mathrm{LSIC}} \boldsymbol{\nabla} \cdot \mathbf{w}_{\mathrm{M}}^{h} \rho r_{\mathrm{C}}^{h} \mathrm{~d} Q \\
&-\sum_{e=1}^{\left(n_{\mathrm{el}}\right)_{n}} \int_{Q_{n}^{e}} \tau_{\mathrm{SUPS}} \mathbf{w}^{h} \cdot\left(\mathbf{r}_{\mathrm{M}}^{h} \cdot \nabla \mathbf{u}^{h}\right) \mathrm{d} Q \\
&+\sum_{e=1}^{\left(n_{\mathrm{el}}\right)_{n}} \int_{Q_{n}^{e}} \frac{\tau_{\mathrm{SUPS}}^{2}}{\rho} \mathbf{r}_{\mathrm{M}}^{h} \cdot\left(\nabla \mathbf{w}^{h}\right) \cdot \mathbf{r}_{\mathrm{M}}^{h} \mathrm{~d} Q \\
&= 0,
\end{aligned}
$$


where

$\mathbf{r}_{\mathrm{M}}^{h}=\rho\left(\frac{\partial \mathbf{u}^{h}}{\partial t}+\mathbf{u}^{h} \cdot \nabla \mathbf{u}^{h}-\mathbf{f}^{h}\right)-\nabla \cdot \boldsymbol{\sigma}^{h}$,

$r_{\mathrm{C}}^{h}=\nabla \cdot \mathbf{u}^{h}$

are the residuals of the momentum equation and incompressibility constraint. Here, $\rho, \mathbf{u}, p, \mathbf{f}$, and $\mathbf{h}$ are the density, velocity, pressure, body force, and the stress specified at the boundary. The stress tensor is defined as $\boldsymbol{\sigma}=-p \mathbf{I}+2 \mu \boldsymbol{\varepsilon}(\mathbf{u})$, where $\mathbf{I}$ is the identity tensor, $\mu=\rho v$ is the viscosity, $v$ is the kinematic viscosity, and $\varepsilon(\mathbf{u})=\left((\nabla \mathbf{u})+(\nabla \mathbf{u})^{T}\right) / 2$ is the strain-rate tensor. The test functions associated with the $\mathbf{u}$ and $p$ are $\mathbf{w}$ and $q$. A superscript " $h$ " indicates that the function is coming from a finite-dimensional space. The symbol $Q_{n}$ represents the $\mathrm{ST}$ slice between time levels $n$ and $n+1$, $\left(P_{n}\right)_{\mathrm{h}}$ is the part of the slice lateral boundary associated with the boundary condition $\mathbf{h}$, and $\Omega_{n}$ is the spatial domain at time level $n$. The superscript " $e$ " is the ST element counter, and $n_{\mathrm{el}}$ is the number of ST elements. The functions are discontinuous in time at each time level, and the superscripts "-" and "+" indicate the values of the functions just below and above the time level.

Remark 1 The ST-SUPS can be obtained from the ST-VMS by dropping the eighth and ninth integrations.

The stabilization parameters, $\tau_{\text {SUPS }}$ and $\nu_{\text {LSIC }}$, will be given in "Appendix B1".

\section{A.2 ST-SI}

\section{A.2.1 Two-side formulation (fluid-fluid SI)}

In describing the ST-SI, labels "Side A" and "Side B" will represent the two sides of the SI. The ST-SI version of the formulation given by Eq. (1) includes added boundary terms corresponding to the SI. The boundary terms for the two sides are first added separately, using test functions $\mathbf{w}_{\mathrm{A}}^{h}$ and $q_{\mathrm{A}}^{h}$ and $\mathbf{w}_{\mathrm{B}}^{h}$ and $q_{\mathrm{B}}^{h}$. Then, putting together the terms added to each side, the complete set of terms added becomes

$$
\begin{aligned}
& -\int_{\left(P_{n}\right)_{\mathrm{SI}}}\left(q_{\mathrm{B}}^{h} \mathbf{n}_{\mathrm{B}}-q_{\mathrm{A}}^{h} \mathbf{n}_{\mathrm{A}}\right) \cdot \frac{1}{2}\left(\mathbf{u}_{\mathrm{B}}^{h}-\mathbf{u}_{\mathrm{A}}^{h}\right) \mathrm{d} P \\
& -\int_{\left(P_{n}\right)_{\mathrm{SI}}} \rho \mathbf{w}_{\mathrm{B}}^{h} \cdot \frac{1}{2}\left(\left(\mathcal{F}_{\mathrm{B}}^{h}-\left|\mathcal{F}_{\mathrm{B}}^{h}\right|\right) \mathbf{u}_{\mathrm{B}}^{h}\right. \\
& \left.-\left(\mathcal{F}_{\mathrm{B}}^{h}-\left|\mathcal{F}_{\mathrm{B}}^{h}\right|\right) \mathbf{u}_{\mathrm{A}}^{h}\right) \mathrm{d} P \\
& -\int_{\left(P_{n}\right)_{\mathrm{SI}}} \rho \mathbf{w}_{\mathrm{A}}^{h} \cdot \frac{1}{2}\left(\left(\mathcal{F}_{\mathrm{A}}^{h}-\left|\mathcal{F}_{\mathrm{A}}^{h}\right|\right) \mathbf{u}_{\mathrm{A}}^{h}\right. \\
& \left.\quad-\left(\mathcal{F}_{\mathrm{A}}^{h}-\left|\mathcal{F}_{\mathrm{A}}^{h}\right|\right) \mathbf{u}_{\mathrm{B}}^{h}\right) \mathrm{d} P
\end{aligned}
$$

$$
\begin{aligned}
& +\int_{\left(P_{n}\right)_{\mathrm{SI}}}\left(\mathbf{n}_{\mathrm{B}} \cdot \mathbf{w}_{\mathrm{B}}^{h}+\mathbf{n}_{\mathrm{A}} \cdot \mathbf{w}_{\mathrm{A}}^{h}\right) \frac{1}{2}\left(p_{\mathrm{B}}^{h}+p_{\mathrm{A}}^{h}\right) \mathrm{d} P \\
& -\int_{\left(P_{n}\right)_{\mathrm{SI}}}\left(\mathbf{w}_{\mathrm{B}}^{h}-\mathbf{w}_{\mathrm{A}}^{h}\right) \cdot\left(\hat{\mathbf{n}}_{\mathrm{B}} \cdot \mu\left(\boldsymbol{\varepsilon}\left(\mathbf{u}_{\mathrm{B}}^{h}\right)+\boldsymbol{\varepsilon}\left(\mathbf{u}_{\mathrm{A}}^{h}\right)\right)\right) \mathrm{d} P \\
& -\gamma \int_{\left(P_{n}\right)_{\mathrm{SI}}} \hat{\mathbf{n}}_{\mathrm{B}} \cdot \mu\left(\boldsymbol{\varepsilon}\left(\mathbf{w}_{\mathrm{B}}^{h}\right)+\boldsymbol{\varepsilon}\left(\mathbf{w}_{\mathrm{A}}^{h}\right)\right) \cdot\left(\mathbf{u}_{\mathrm{B}}^{h}-\mathbf{u}_{\mathrm{A}}^{h}\right) \mathrm{d} P \\
& +\int_{\left(P_{n}\right)_{\mathrm{SI}}} \frac{\mu C}{h}\left(\mathbf{w}_{\mathrm{B}}^{h}-\mathbf{w}_{\mathrm{A}}^{h}\right) \cdot\left(\mathbf{u}_{\mathrm{B}}^{h}-\mathbf{u}_{\mathrm{A}}^{h}\right) \mathrm{d} P
\end{aligned}
$$

where

$\mathcal{F}_{\mathrm{B}}^{h}=\mathbf{n}_{\mathrm{B}} \cdot\left(\mathbf{u}_{\mathrm{B}}^{h}-\mathbf{v}_{\mathrm{B}}^{h}\right)$,

$\mathcal{F}_{\mathrm{A}}^{h}=\mathbf{n}_{\mathrm{A}} \cdot\left(\mathbf{u}_{\mathrm{A}}^{h}-\mathbf{v}_{\mathrm{A}}^{h}\right)$,

$\hat{\mathbf{n}}_{\mathrm{B}}=\frac{\mathbf{n}_{\mathrm{B}}-\mathbf{n}_{\mathrm{A}}}{\left\|\mathbf{n}_{\mathrm{B}}-\mathbf{n}_{\mathrm{A}}\right\|}$.

Here, $\left(P_{n}\right)_{\mathrm{SI}}$ is the SI in the ST domain, $\mathbf{n}$ is the unit normal vector, $\mathbf{v}$ is the mesh velocity, $\gamma=1$, and $C$ is a nondimensional constant. The element length $h$ will be defined in "Appendix B2".

\section{A.2.2 One-side formulation (fluid-solid SI)}

On solid surfaces where we prefer weak enforcement of the Dirichlet conditions [49,51] for the fluid, we use the ST-SI version where the SI is between the fluid and solid domains. This version is obtained (see [14]) by starting with the terms added to Side B and replacing the Side A velocity with the velocity $\mathbf{g}^{h}$ coming from the solid domain. Then the SI terms added to Eq. (1) to represent the weakly-enforced Dirichlet conditions become

$$
\begin{aligned}
& -\int_{\left(P_{n}\right)_{\mathrm{SI}}} q_{\mathrm{B}}^{h} \mathbf{n}_{\mathrm{B}} \cdot \mathbf{u}_{\mathrm{B}}^{h} \mathrm{~d} P-\int_{\left(P_{n}\right)_{\mathrm{SI}}} \rho \mathbf{w}_{\mathrm{B}}^{h} \cdot \mathcal{F}_{\mathrm{B}}^{h} \mathbf{u}_{\mathrm{B}}^{h} \mathrm{~d} P \\
& +\int_{\left(P_{n}\right)_{\mathrm{SI}}} q_{\mathrm{B}}^{h} \mathbf{n}_{\mathrm{B}} \cdot \mathbf{g}^{h} \mathrm{~d} P \\
& +\int_{\left(P_{n}\right)_{\mathrm{SI}}} \rho \mathbf{w}_{\mathrm{B}}^{h} \cdot \frac{1}{2}\left(\left(\mathcal{F}_{\mathrm{B}}^{h}+\left|\mathcal{F}_{\mathrm{B}}^{h}\right|\right) \mathbf{u}_{\mathrm{B}}^{h}\right. \\
& \left.+\left(\mathcal{F}_{\mathrm{B}}^{h}-\left|\mathcal{F}_{\mathrm{B}}^{h}\right|\right) \mathbf{g}^{h}\right) \mathrm{d} P \\
& -\int_{\left(P_{n}\right)_{\mathrm{SI}}} \mathbf{w}_{\mathrm{B}}^{h} \cdot\left(\mathbf{n}_{\mathrm{B}} \cdot \boldsymbol{\sigma}_{\mathrm{B}}^{h}\right) \mathrm{d} P \\
& -\gamma \int_{\left(P_{n}\right)_{\mathrm{SI}}} \mathbf{n}_{\mathrm{B}} \cdot 2 \mu \boldsymbol{\varepsilon}\left(\mathbf{w}_{\mathrm{B}}^{h}\right) \cdot\left(\mathbf{u}_{\mathrm{B}}^{h}-\mathbf{g}^{h}\right) \mathrm{d} P \\
& +\int_{\left(P_{n}\right)_{\mathrm{SI}}} \frac{\mu C}{h_{\mathrm{B}}} \mathbf{w}_{\mathrm{B}}^{h} \cdot\left(\mathbf{u}_{\mathrm{B}}^{h}-\mathbf{g}^{h}\right) \mathrm{d} P .
\end{aligned}
$$

The element length $h_{\mathrm{B}}$ will be given in "Appendix B2". 


\section{B Stabilization parameters}

\section{B.1 ST-VMS}

There are various ways of defining the stabilization parameters $\tau_{\text {SUPS }}$ and $v_{\text {LSIC. }}$ Here, $\tau_{\text {SUPS }}$ is mostly from [137]:

$\tau_{\mathrm{SUPS}}=\left(\tau_{\mathrm{SUGN} 12}^{-2}+\tau_{\mathrm{SUGN} 3}^{-2}+\tau_{\mathrm{SUGN} 4}^{-2}\right)^{-\frac{1}{2}}$.

The first and second components are given as

$\tau_{\mathrm{SUGN} 12}^{-2}=\left[\begin{array}{l}1 \\ \mathbf{u}\end{array}\right]\left[\begin{array}{l}1 \\ \mathbf{u}\end{array}\right]: \mathbf{G}^{\mathrm{ST}}$

and

$\tau_{\mathrm{SUGN} 3}^{-1}=\nu \mathbf{r r}: \mathbf{G}$,

where $\mathbf{r}$ is the solution-gradient direction:

$\mathbf{r}=\frac{\nabla\|\mathbf{u}\|}{\|\nabla\| \mathbf{u}\|\|}$

Here $\mathbf{G}^{\mathbf{S T}}$ and $\mathbf{G}$ are the $\mathbf{S T}$ and space-only element metric tensors:

$$
\begin{aligned}
\mathbf{G}^{\mathrm{ST}} & =\left(\hat{\mathbf{Q}}^{\mathrm{ST}}\right)^{-T} \cdot\left(\hat{\mathbf{Q}}^{\mathrm{ST}}\right)^{-1}, \\
\mathbf{G} & =\hat{\mathbf{Q}}^{-T} \cdot \hat{\mathbf{Q}}^{-1},
\end{aligned}
$$

where

$$
\begin{aligned}
\hat{\mathbf{Q}}^{\mathrm{ST}} & =\mathbf{Q}^{\mathrm{ST}} \cdot\left(\mathbf{D}^{\mathrm{ST}}\right)^{-1}, \\
\hat{\mathbf{Q}} & =\mathbf{Q} \cdot \mathbf{D}^{-1} .
\end{aligned}
$$

The ST and space-only Jacobian tensors are

$$
\mathbf{Q}^{\mathrm{ST}}=\left[\begin{array}{ll}
\frac{\partial t}{\partial \theta} & \frac{\partial t}{\partial \boldsymbol{\xi}} \\
\frac{\partial \mathbf{x}}{\partial \theta} & \mathbf{Q}
\end{array}\right]
$$

and

$\mathbf{Q}=\frac{\partial \mathbf{x}}{\partial \boldsymbol{\xi}}$,

where $\theta$ and $\boldsymbol{\xi}$ are the temporal and spatial parametric coordinates. The transformation tensor $\mathbf{D}^{\mathrm{ST}}$ is defined as

$\mathbf{D}^{\mathrm{ST}}=\left[\begin{array}{cc}D_{\theta} & \mathbf{0}^{T} \\ \mathbf{0} & \mathbf{D}\end{array}\right]$.

The definitions used for $D_{\theta}$ and $\mathbf{D}$ play an important role, especially for higher-order isogeometric discretization [137,
139] and simplex elements [138]. However, in this article, we use $D_{\theta}=1$ and $\mathbf{D}=\mathbf{I}$.

The third component, originating from [7], is defined as

$\tau_{\mathrm{SUGN} 4}=\left\|\boldsymbol{\nabla} \mathbf{u}^{h}\right\|_{F}^{-1}$,

where $\|\cdot\|_{F}$ represents the Frobenius norm.

The stabilization parameter $v_{\text {LSIC }}$ is from [30]:

$\nu_{\mathrm{LSIC}}=\frac{h_{\mathrm{LSIC}}^{2}}{\tau_{\mathrm{SUPS}}}$

where $h_{\text {LSIC }}$ is set equal to the minimum element length $h_{\text {MIN }}$ :

$h_{\mathrm{MIN}}=2\left(\max _{\mathbf{r}}(\mathbf{r r}: \mathbf{G})\right)^{-\frac{1}{2}}$.

For more ways of calculating the stabilization parameters in flow computations, see [86,136,140-151].

\section{B.2 ST-SI}

The element length used in the ST-SI is given as

$$
\begin{array}{rlrl}
h & =\left(\frac{h_{\mathrm{B}}^{-1}+h_{\mathrm{A}}^{-1}}{2}\right)^{-1}, & \\
h_{\mathrm{B}} & =2\left(\mathbf{n}_{\mathrm{B}} \mathbf{n}_{\mathrm{B}}: \mathbf{G}\right)^{-\frac{1}{2}} & & \text { (for Side B), } \\
h_{\mathrm{A}} & =2\left(\mathbf{n}_{\mathrm{A}} \mathbf{n}_{\mathrm{A}}: \mathbf{G}\right)^{-\frac{1}{2}} & & (\text { for Side A). }
\end{array}
$$

These were introduced in [127].

\section{References}

1. Tezduyar TE, Schwaab M, Sathe S (2009) Sequentially-coupled arterial fluid-structure interaction (SCAFSI) technique. Comput Methods Appl Mech Eng 198:3524-3533. https://doi.org/10. 1016/j.cma.2008.05.024

2. Tezduyar TE, Takizawa K, Moorman C, Wright S, Christopher J (2010) Multiscale sequentially-coupled arterial FSI technique. Comput Mech 46:17-29. https://doi.org/10.1007/s00466-0090423-2

3. Tezduyar TE, Takizawa K, Moorman C, Wright S, Christopher J (2010) Space-time finite element computation of complex fluidstructure interactions. Int J Numer Methods Fluids 64:1201-1218. https://doi.org/10.1002/fld.2221

4. Hsu M-C, Kamensky D, Xu F, Kiendl J, Wang C, Wu MCH, Mineroff J, Reali A, Bazilevs Y, Sacks MS (2015) Dynamic and fluid-structure interaction simulations of bioprosthetic heart valves using parametric design with T-splines and Fung-type material models. Comput Mech 55:1211-1225. https://doi.org/ 10.1007/s00466-015-1166-x

5. Takizawa K, Tezduyar TE (2011) Multiscale space-time fluidstructure interaction techniques. Comput Mech 48:247-267. https://doi.org/10.1007/s00466-011-0571-z 
6. Takizawa K, Tezduyar TE (2012) Space-time fluidstructure interaction methods. Math Models Methods Appl Sci 22(supp02):1230001. https://doi.org/10.1142/ S0218202512300013

7. Takizawa K, Tezduyar TE, Kuraishi T (2015) Multiscale ST methods for thermo-fluid analysis of a ground vehicle and its tires. Math Models Methods Appl Sci 25:2227-2255. https://doi.org/ $10.1142 / \mathrm{S} 0218202515400072$

8. Hughes TJR (1995) Multiscale phenomena: Green's functions, the Dirichlet-to-Neumann formulation, subgrid scale models, bubbles, and the origins of stabilized methods. Comput Methods Appl Mech Eng 127:387-401

9. Hughes TJR, Oberai AA, Mazzei L (2001) Large eddy simulation of turbulent channel flows by the variational multiscale method. Phys Fluids 13:1784-1799

10. Bazilevs Y, Calo VM, Cottrell JA, Hughes TJR, Reali A, Scovazzi G (2007) Variational multiscale residual-based turbulence modeling for large eddy simulation of incompressible flows. Comput Methods Appl Mech Eng 197:173-201

11. Bazilevs Y, Akkerman I (2010) Large eddy simulation of turbulent Taylor-Couette flow using isogeometric analysis and the residualbased variational multiscale method. J Comput Phys 229:34023414

12. Takizawa K, Tezduyar TE, Buscher A, Asada S (2014) Spacetime interface-tracking with topology change (ST-TC). Comput Mech 54:955-971. https://doi.org/10.1007/s00466-013-0935-7

13. Takizawa K, Tezduyar TE, Buscher A, Asada S (2014) Spacetime fluid mechanics computation of heart valve models. Comput Mech 54:973-986. https://doi.org/10.1007/s00466-014-1046-9

14. Takizawa K, Tezduyar TE, Mochizuki H, Hattori H, Mei S, Pan L, Montel K (2015) Space-time VMS method for flow computations with slip interfaces (ST-SI). Math Models Methods Appl Sci 25:2377-2406. https://doi.org/10.1142/S0218202515400126

15. Takizawa K, Tezduyar TE, Kuraishi T, Tabata S, Takagi H (2016) Computational thermo-fluid analysis of a disk brake. Comput Mech 57:965-977. https://doi.org/10.1007/s00466-016-1272-4

16. Takizawa K, Henicke B, Puntel A, Spielman T, Tezduyar TE (2012) Space-time computational techniques for the aerodynamics of flapping wings. J Appl Mech 79:010903. https://doi.org/10. $1115 / 1.4005073$

17. Takizawa K, Tezduyar TE, Otoguro Y, Terahara T, Kuraishi T, Hattori H (2017) Turbocharger flow computations with the spacetime isogeometric analysis (ST-IGA). Comput Fluids 142:15-20. https://doi.org/10.1016/j.compfluid.2016.02.021

18. Takizawa K, Tezduyar TE, Asada S, Kuraishi T (2016) Spacetime method for flow computations with slip interfaces and topology changes (ST-SI-TC). Comput Fluids 141:124-134. https:// doi.org/10.1016/j.compfluid.2016.05.006

19. Takizawa K, Tezduyar TE, Terahara T, Sasaki T (2018) Heart valve flow computation with the space-time slip interface topology change (ST-SI-TC) method and isogeometric analysis (IGA). In: Wriggers P, Lenarz T (eds) Biomedical technology: modeling, experiments and simulation, Lecture notes in applied and computational mechanics, Springer, pp 77-99. ISBN 978-3-31959547-4. https://doi.org/10.1007/978-3-319-59548-1_6

20. Takizawa K, Tezduyar TE, Terahara T, Sasaki T (2017) Heart valve flow computation with the integrated space-time VMS, slip interface, topology change and isogeometric discretization methods. Comput Fluids 158:176-188. https://doi.org/10.1016/j. compfluid.2016.11.012

21. Tezduyar T, Aliabadi S, Behr M (1998) Enhanced-discretization interface-capturing technique (EDICT) for computation of unsteady flows with interfaces. Comput Method Appl Mech Eng 155:235-248. https://doi.org/10.1016/S0045-7825(97)00194-1
22. Bazilevs Y, Takizawa K, Tezduyar TE (2013) Computational fluid-structure interaction: methods and applications. Wiley, New York. ISBN 978-0470978771

23. Takizawa K, Henicke B, Tezduyar TE, Hsu M-C, Bazilevs Y (2011) Stabilized space-time computation of wind-turbine rotor aerodynamics. Comput Mech 48:333-344. https://doi.org/10. 1007/s00466-011-0589-2

24. Tezduyar TE, Behr M, Mittal S, Johnson AA (1992) Computation of unsteady incompressible flows with the finite element methods: space-time formulations, iterative strategies and massively parallel implementations. In: New methods in transient analysis, PVP, vol 246/AMD-143, ASME, New York, pp 7-24

25. Tezduyar T, Aliabadi S, Behr M, Johnson A, Mittal S (1993) Parallel finite-element computation of 3D flows. Computer 26(10):2736. https://doi.org/10.1109/2.237441

26. Johnson AA, Tezduyar TE (1994) Mesh update strategies in parallel finite element computations of flow problems with moving boundaries and interfaces. Comput Methods Appl Mech Eng 119:73-94. https://doi.org/10.1016/0045-7825(94)00077-8

27. Tezduyar TE (2001) Finite element methods for flow problems with moving boundaries and interfaces. Arch Comput Methods Eng 8:83-130. https://doi.org/10.1007/BF02897870

28. Tezduyar TE, Sathe S (2007) Modeling of fluid-structure interactions with the space-time finite elements: solution techniques. Int J Numer Methods Fluids 54:855-900. https://doi.org/10.1002/ fld. 1430

29. Takizawa K, Henicke B, Puntel A, Kostov N, Tezduyar TE (2012) Space-time techniques for computational aerodynamics modeling of flapping wings of an actual locust. Comput Mech 50:743-760. https://doi.org/10.1007/s00466-012-0759-x

30. Takizawa K, Tezduyar TE, McIntyre S, Kostov N, Kolesar R, Habluetzel C (2014) Space-time VMS computation of windturbine rotor and tower aerodynamics. Comput Mech 53:1-15. https://doi.org/10.1007/s00466-013-0888-x

31. Takizawa K, Tezduyar TE, Boben J, Kostov N, Boswell C, Buscher A (2013) Fluid-structure interaction modeling of clusters of spacecraft parachutes with modified geometric porosity. Comput Mech 52:1351-1364. https://doi.org/10.1007/s00466013-0880-5

32. Takizawa K, Tezduyar TE, Buscher A (2015) Space-time computational analysis of MAV flapping-wing aerodynamics with wing clapping. Comput Mech 55:1131-1141. https://doi.org/10.1007/ s00466-014-1095-0

33. Tezduyar TE, Sathe S, Pausewang J, Schwaab M, Christopher J, Crabtree J (2008) Interface projection techniques for fluid-structure interaction modeling with moving-mesh methods. Comput Mech 43:39-49. https://doi.org/10.1007/s00466008-0261-7

34. Tezduyar TE, Schwaab M, Sathe S (2007) Arterial fluid mechanics with the sequentially-coupled arterial FSI technique. In: Onate E, Papadrakakis M, Schrefler B (eds) Coupled problems 2007. CIMNE, Barcelona

35. Tezduyar TE, Sathe S, Schwaab M, Conklin BS (2008) Arterial fluid mechanics modeling with the stabilized space-time fluid-structure interaction technique. Int J Numer Methods Fluids 57:601-629. https://doi.org/10.1002/fld.1633

36. Tezduyar TE, Takizawa K, Christopher J (2009) Multiscale sequentially-coupled arterial fluid-structure interaction (SCAFSI) technique. In: Hartmann S, Meister A, Schafer $\mathrm{M}$, Turek S (eds) International workshop on fluid-structure interaction - theory, numerics and applications, Kassel University Press, pp 231-252. ISBN 978-3-89958-666-4 
37. Tezduyar TE, Takizawa K, Christopher J, Moorman C, Wright S (2009) Interface projection techniques for complex FSI problems. In: Kvamsdal T, Pettersen B, Bergan P, Onate E, Garcia J (eds) Marine 2009. CIMNE, Barcelona

38. Tezduyar TE (1992) Stabilized finite element formulations for incompressible flow computations. Adv Appl Mech 28:1-44. https://doi.org/10.1016/S0065-2156(08)70153-4

39. Tezduyar TE (2003) Computation of moving boundaries and interfaces and stabilization parameters. Int J Numer Methods Fluids 43:555-575. https://doi.org/10.1002/fld.505

40. Brooks AN, Hughes TJR (1982) Streamline upwind/PetrovGalerkin formulations for convection dominated flows with particular emphasis on the incompressible Navier-Stokes equations. Comput Methods Appl Mech Eng 32:199-259

41. Hughes TJR, Liu WK, Zimmermann TK (1981) LagrangianEulerian finite element formulation for incompressible viscous flows. Comput Methods Appl Mech Eng 29:329-349

42. Bazilevs Y, Calo VM, Hughes TJR, Zhang Y (2008) Isogeometric fluid-structure interaction: theory, algorithms, and computations. Comput Mech 43:3-37

43. Takizawa K, Bazilevs Y, Tezduyar TE (2012) Space-time and ALE-VMS techniques for patient-specific cardiovascular fluidstructure interaction modeling. Arch Comput Methods Eng 19:171-225. https://doi.org/10.1007/s11831-012-9071-3

44. Bazilevs Y, Hsu M-C, Takizawa K, Tezduyar TE (2012) ALEVMS and ST-VMS methods for computer modeling of windturbine rotor aerodynamics and fluid-structure interaction. Math Models Methods Appl Sci 22(supp02):1230002. https://doi.org/ 10.1142/S0218202512300025

45. Bazilevs Y, Takizawa K, Tezduyar TE (2013) Challenges and directions in computational fluid-structure interaction. Math Models Methods Appl Sci 23:215-221. https://doi.org/10.1142/ S0218202513400010

46. Bazilevs Y, Takizawa K, Tezduyar TE (2015) New directions and challenging computations in fluid dynamics modeling with stabilized and multiscale methods. Math Models Methods Appl Sci 25:2217-2226. https://doi.org/10.1142/S0218202515020029

47. Bazilevs Y, Takizawa K, Tezduyar TE (2019) Computational analysis methods for complex unsteady flow problems. Math Models Methods Appl Sci 29:825-838. https://doi.org/10.1142/ S0218202519020020

48. Kalro V, Tezduyar TE (2000) A parallel 3D computational method for fluid-structure interactions in parachute systems. Comput Methods Appl Mech Eng 190:321-332. https://doi.org/10.1016/ S0045-7825(00)00204-8

49. Bazilevs Y, Hughes TJR (2007) Weak imposition of Dirichlet boundary conditions in fluid mechanics. Comput Fluids 36:1226

50. Bazilevs Y, Michler C, Calo VM, Hughes TJR (2010) Isogeometric variational multiscale modeling of wall-bounded turbulent flows with weakly enforced boundary conditions on unstretched meshes. Math Models Methods Appl Sci 199:780-790

51. Hsu M-C, Akkerman I, Bazilevs Y (2012) Wind turbine aerodynamics using ALE-VMS: validation and role of weakly enforced boundary conditions. Comput Mech 50:499-511

52. Bazilevs Y, Hughes TJR (2008) NURBS-based isogeometric analysis for the computation of flows about rotating components. Comput Mech 43:143-150

53. Hsu M-C, Bazilevs Y (2012) Fluid-structure interaction modeling of wind turbines: simulating the full machine. Comput Mech 50:821-833

54. Bazilevs Y, Hsu M-C, Akkerman I, Wright S, Takizawa K, Henicke B, Spielman T, Tezduyar TE (2011) 3D simulation of wind turbine rotors at full scale. Part I: geometry modeling and aerodynamics. Int J Numer Methods Fluids 65:207-235. https:// doi.org/10.1002/fld.2400
55. Bazilevs Y, Hsu M-C, Kiendl J, Wüchner R, Bletzinger K-U (2011) 3D simulation of wind turbine rotors at full scale. Part II: fluid-structure interaction modeling with composite blades. Int $\mathrm{J}$ Numer Methods Fluids 65:236-253

56. Hsu M-C, Akkerman I, Bazilevs Y (2011) High-performance computing of wind turbine aerodynamics using isogeometric analysis. Comput Fluids 49:93-100

57. Bazilevs Y, Hsu M-C, Scott MA (2012) Isogeometric fluidstructure interaction analysis with emphasis on non-matching discretizations, and with application to wind turbines. Comput Methods Appl Mech Eng 249-252:28-41

58. Hsu M-C, Akkerman I, Bazilevs Y (2014) Finite element simulation of wind turbine aerodynamics: validation study using NREL Phase VI experiment. Wind Energy 17:461-481

59. Korobenko A, Hsu M-C, Akkerman I, Tippmann J, Bazilevs Y (2013) Structural mechanics modeling and FSI simulation of wind turbines. Math Models Methods Appl Sci 23:249-272

60. Bazilevs Y, Takizawa K, Tezduyar TE, Hsu M-C, Kostov N, McIntyre S (2014) Aerodynamic and FSI analysis of wind turbines with the ALE-VMS and ST-VMS methods. Arch Comput Methods Eng 21:359-398. https://doi.org/10.1007/s11831-014-9119-7

61. Bazilevs Y, Korobenko A, Deng X, Yan J (2015) Novel structural modeling and mesh moving techniques for advanced FSI simulation of wind turbines. Int J Numer Methods Eng 102:766-783. https://doi.org/10.1002/nme.4738

62. Korobenko A, Yan J, Gohari SMI, Sarkar S, Bazilevs Y (2017) FSI simulation of two back-to-back wind turbines in atmospheric boundary layer flow. Comput Fluids 158:167-175. https://doi.org/ 10.1016/j.compfluid.2017.05.010

63. Korobenko A, Bazilevs Y, Takizawa K, Tezduyar TE (2018) Recent advances in ALE-VMS and ST-VMS computational aerodynamic and FSI analysis of wind turbines. In: Tezduyar TE (ed) Frontiers in computational fluid-structure interaction and flow simulation: research from lead investigators under forty-2018, modeling and simulation in science, engineering and technology, Springer, pp 253-336. ISBN 978-3-319-96468-3. https://doi.org/ 10.1007/978-3-319-96469-0_7

64. Korobenko A, Bazilevs Y, Takizawa K, Tezduyar TE (2019) Computer modeling of wind turbines: 1. ALE-VMS and STVMS aerodynamic and FSI analysis. Arch Comput Methods Eng 26:1059-1099. https://doi.org/10.1007/s11831-018-9292-1

65. Korobenko A, Hsu M-C, Akkerman I, Bazilevs Y (2013) Aerodynamic simulation of vertical-axis wind turbines. J Appl Mech 81:021011. https://doi.org/10.1115/1.4024415

66. Bazilevs Y, Korobenko A, Deng X, Yan J, Kinzel M, Dabiri JO (2014) FSI modeling of vertical-axis wind turbines. J Appl Mech 81:081006. https://doi.org/10.1115/1.4027466

67. Yan J, Korobenko A, Deng X, Bazilevs Y (2016) Computational free-surface fluid-structure interaction with application to floating offshore wind turbines. Comput Fluids 141:155-174. https://doi. org/10.1016/j.compfluid.2016.03.008

68. Bazilevs Y, Korobenko A, Yan J, Pal A, Gohari SMI, Sarkar S (2015) ALE-VMS formulation for stratified turbulent incompressible flows with applications. Math Models Methods Appl Sci 25:2349-2375. https://doi.org/10.1142/S0218202515400114

69. Bazilevs Y, Korobenko A, Deng X, Yan J (2016) FSI modeling for fatigue-damage prediction in full-scale wind-turbine blades. $\mathrm{J}$ Appl Mech 83(6):061010

70. Bazilevs Y, Calo VM, Zhang Y, Hughes TJR (2006) Isogeometric fluid-structure interaction analysis with applications to arterial blood flow. Comput Mech 38:310-322

71. Bazilevs Y, Gohean JR, Hughes TJR, Moser RD, Zhang Y (2009) Patient-specific isogeometric fluid-structure interaction analysis of thoracic aortic blood flow due to implantation of the Jarvik 2000 left ventricular assist device. Comput Methods Appl Mech Eng 198:3534-3550 
72. Bazilevs Y, Hsu M-C, Benson D, Sankaran S, Marsden A (2009) Computational fluid-structure interaction: methods and application to a total cavopulmonary connection. Comput Mech 45:77-89

73. Bazilevs Y, Hsu M-C, Zhang Y, Wang W, Liang X, Kvamsdal T, Brekken R, Isaksen J (2010) A fully-coupled fluid-structure interaction simulation of cerebral aneurysms. Comput Mech 46:3-16

74. Bazilevs Y, Hsu M-C, Zhang Y, Wang W, Kvamsdal T, Hentschel S, Isaksen J (2010) Computational fluid-structure interaction: methods and application to cerebral aneurysms. Biomech Model Mechanobiol 9:481-498

75. Hsu M-C, Bazilevs Y (2011) Blood vessel tissue prestress modeling for vascular fluid-structure interaction simulations. Finite Elem Anal Des 47:593-599

76. Long CC, Marsden AL, Bazilevs Y (2013) Fluid-structure interaction simulation of pulsatile ventricular assist devices. Comput Mech 52:971-981. https://doi.org/10.1007/s00466-013-0858-3

77. Long CC, Esmaily-Moghadam M, Marsden AL, Bazilevs Y (2014) Computation of residence time in the simulation of pulsatile ventricular assist devices. Comput Mech 54:911-919. https://doi.org/10.1007/s00466-013-0931-y

78. Long CC, Marsden AL, Bazilevs Y (2014) Shape optimization of pulsatile ventricular assist devices using FSI to minimize thrombotic risk. Comput Mech 54:921-932. https://doi.org/10.1007/ s00466-013-0967-z

79. Hsu M-C, Kamensky D, Bazilevs Y, Sacks MS, Hughes TJR (2014) Fluid-structure interaction analysis of bioprosthetic heart valves: significance of arterial wall deformation. Comput Mech 54:1055-1071. https://doi.org/10.1007/s00466-014-1059-4

80. Kamensky D, Hsu M-C, Schillinger D, Evans JA, Aggarwal A, Bazilevs Y, Sacks MS, Hughes TJR (2015) An immersogeometric variational framework for fluid-structure interaction: application to bioprosthetic heart valves. Comput Methods Appl Mech Eng 284:1005-1053

81. Akkerman I, Bazilevs Y, Benson DJ, Farthing MW, Kees CE (2012) Free-surface flow and fluid-object interaction modeling with emphasis on ship hydrodynamics. J Appl Mech 79:010905

82. Akkerman I, Dunaway J, Kvandal J, Spinks J, Bazilevs Y (2012) Toward free-surface modeling of planing vessels: simulation of the Fridsma hull using ALE-VMS. Comput Mech 50:719-727

83. Wang C, Wu MCH, Xu F, Hsu M-C, Bazilevs Y (2017) Modeling of a hydraulic arresting gear using fluid-structure interaction and isogeometric analysis. Comput Fluids 142:3-14. https://doi.org/ 10.1016/j.compfluid.2015.12.004

84. Wu MCH, Kamensky D, Wang C, Herrema AJ, Xu F, Pigazzini MS, Verma A, Marsden AL, Bazilevs Y, Hsu M-C (2017) Optimizing fluid-structure interaction systems with immersogeometric analysis and surrogate modeling: application to a hydraulic arresting gear. Comput Methods Appl Mech Eng 316:668-693

85. Yan J, Deng X, Korobenko A, Bazilevs Y (2017) Free-surface flow modeling and simulation of horizontal-axis tidal-stream turbines. Comput Fluids 158:157-166. https://doi.org/10.1016/ j.compfluid.2016.06.016

86. Castorrini A, Corsini A, Rispoli F, Takizawa K, Tezduyar TE (2019) A stabilized ALE method for computational fluidstructure interaction analysis of passive morphing in turbomachinery. Math Models Methods Appl Sci 29:967-994. https://doi. org/10.1142/S0218202519410057

87. Augier B, Yan J, Korobenko A, Czarnowski J, Ketterman G, Bazilevs Y (2015) Experimental and numerical FSI study of compliant hydrofoils. Comput Mech 55:1079-1090. https://doi.org/ 10.1007/s00466-014-1090-5

88. Yan J, Augier B, Korobenko A, Czarnowski J, Ketterman G, Bazilevs Y (2016) FSI modeling of a propulsion system based on compliant hydrofoils in a tandem configuration. Comput Fluids 141:201-211. https://doi.org/10.1016/j.compfluid.2015.07.013
89. Helgedagsrud TA, Bazilevs Y, Mathisen KM, Oiseth OA (2019) Computational and experimental investigation of free vibration and flutter of bridge decks. Comput Mech. https://doi.org/10. 1007/s00466-018-1587-4

90. Helgedagsrud TA, Bazilevs Y, Korobenko A, Mathisen KM, Oiseth OA (2019) Using ALE-VMS to compute aerodynamic derivatives of bridge sections. Comput Fluids. https://doi.org/10. 1016/j.compfluid.2018.04.037

91. Helgedagsrud TA, Akkerman I, Bazilevs Y, Mathisen KM, Oiseth OA (2019) Isogeometric modeling and experimental investigation of moving-domain bridge aerodynamics. ASCE J Eng Mech 145:04019026

92. Kamensky D, Evans JA, Hsu M-C, Bazilevs Y (2017) Projectionbased stabilization of interface Lagrange multipliers in immersogeometric fluid-thin structure interaction analysis, with application to heart valve modeling. Comput Math Appl 74:2068-2088. https://doi.org/10.1016/j.camwa.2017.07.006

93. Yu Y, Kamensky D, Hsu M-C, Lu XY, Bazilevs Y, Hughes TJR (2018) Error estimates for projection-based dynamic augmented Lagrangian boundary condition enforcement, with application to fluid-structure interaction. Math Models Methods Appl Sci 28:2457-2509. https://doi.org/10.1142/S0218202518500537

94. Yan J, Korobenko A, Tejada-Martinez AE, Golshan R, Bazilevs $Y$ (2017) A new variational multiscale formulation for stratified incompressible turbulent flows. Comput Fluids 158:150-156. https://doi.org/10.1016/j.compfluid.2016.12.004

95. van Opstal TM, Yan J, Coley C, Evans JA, Kvamsdal T, Bazilevs Y (2017) Isogeometric divergence-conforming variational multiscale formulation of incompressible turbulent flows. Comput Methods Appl Mech Eng 316:859-879. https://doi.org/10.1016/ j.cma.2016.10.015

96. Xu F, Moutsanidis G, Kamensky D, Hsu M-C, Murugan M, Ghoshal A, Bazilevs Y (2017) Compressible flows on moving domains: stabilized methods, weakly enforced essential boundary conditions, sliding interfaces, and application to gas-turbine modeling. Comput Fluids 158:201-220. https://doi.org/10.1016/ j.compfluid.2017.02.006

97. Tezduyar TE, Takizawa K (2019) Space-time computations in practical engineering applications: a summary of the 25-year history. Comput Mech 63:747-753. https://doi.org/10.1007/s00466018-1620-7

98. Takizawa K, Tezduyar TE (2012) Computational methods for parachute fluid-structure interactions. Arch Comput Methods Eng 19:125-169. https://doi.org/10.1007/s11831-012-9070-4

99. Takizawa K, Fritze M, Montes D, Spielman T, Tezduyar TE (2012) Fluid-structure interaction modeling of ringsail parachutes with disreefing and modified geometric porosity. Comput Mech 50:835-854. https://doi.org/10.1007/s00466-012-0761-3

100. Takizawa K, Tezduyar TE, Boswell C, Tsutsui Y, Montel K (2015) Special methods for aerodynamic-moment calculations from parachute FSI modeling. Comput Mech 55:1059-1069. https://doi.org/10.1007/s00466-014-1074-5

101. Takizawa K, Montes D, Fritze M, McIntyre S, Boben J, Tezduyar TE (2013) Methods for FSI modeling of spacecraft parachute dynamics and cover separation. Math Models Methods Appl Sci 23:307-338. https://doi.org/10.1142/S0218202513400058

102. Takizawa K, Tezduyar TE, Boswell C, Kolesar R, Montel K (2014) FSI modeling of the reefed stages and disreefing of the Orion spacecraft parachutes. Comput Mech 54:1203-1220. https://doi. org/10.1007/s00466-014-1052-y

103. Takizawa K, Tezduyar TE, Kolesar R, Boswell C, Kanai T, Montel K (2014) Multiscale methods for gore curvature calculations from FSI modeling of spacecraft parachutes. Comput Mech 54:14611476. https://doi.org/10.1007/s00466-014-1069-2 
104. Takizawa K, Tezduyar TE, Kolesar R (2015) FSI modeling of the Orion spacecraft drogue parachutes. Comput Mech 55:11671179. https://doi.org/10.1007/s00466-014-1108-z

105. Takizawa K, Henicke B, Montes D, Tezduyar TE, Hsu MC, Bazilevs Y (2011) Numerical-performance studies for the stabilized space-time computation of wind-turbine rotor aerodynamics. Comput Mech 48:647-657. https://doi.org/10.1007/ s00466-011-0614-5

106. Takizawa K, Bazilevs Y, Tezduyar TE, Hsu M-C, Øiseth O, Mathisen KM, Kostov N, McIntyre S (2014) Engineering analysis and design with ALE-VMS and space-time methods. Arch Comput Methods Eng 21:481-508. https://doi.org/10.1007/s11831014-9113-0

107. Takizawa $\mathrm{K}$ (2014) Computational engineering analysis with the new-generation space-time methods. Comput Mech 54:193-211. https://doi.org/10.1007/s00466-014-0999-z

108. Takizawa K, Henicke B, Puntel A, Kostov N, Tezduyar TE (2013) Computer modeling techniques for flapping-wing aerodynamics of a locust. Comput Fluids 85:125-134. https://doi.org/10.1016/ j.compfluid.2012.11.008

109. Takizawa K, Kostov N, Puntel A, Henicke B, Tezduyar TE (2012) Space-time computational analysis of bio-inspired flapping-wing aerodynamics of a micro aerial vehicle. Comput Mech 50:761778. https://doi.org/10.1007/s00466-012-0758-y

110. Takizawa K, Tezduyar TE, Kostov N (2014) Sequentially-coupled space-time FSI analysis of bio-inspired flapping-wing aerodynamics of an MAV. Comput Mech 54:213-233. https://doi.org/ 10.1007/s00466-014-0980-x

111. Takizawa K, Bazilevs Y, Tezduyar TE, Long CC, Marsden AL, Schjodt K (2014) ST and ALE-VMS methods for patientspecific cardiovascular fluid mechanics modeling. Math Models Methods Appl Sci 24:2437-2486. https://doi.org/10.1142/ S0218202514500250

112. Takizawa K, Schjodt K, Puntel A, Kostov N, Tezduyar TE (2012) Patient-specific computer modeling of blood flow in cerebral arteries with aneurysm and stent. Comput Mech 50:675-686. https://doi.org/10.1007/s00466-012-0760-4

113. Takizawa K, Schjodt K, Puntel A, Kostov N, Tezduyar TE (2013) Patient-specific computational analysis of the influence of a stent on the unsteady flow in cerebral aneurysms. Comput Mech 51:1061-1073. https://doi.org/10.1007/s00466-012-0790y

114. Suito H, Takizawa K, Huynh VQH, Sze D, Ueda T (2014) FSI analysis of the blood flow and geometrical characteristics in the thoracic aorta. Comput Mech 54:1035-1045. https://doi.org/10. 1007/s00466-014-1017-1

115. Suito H, Takizawa K, Huynh VQH, Sze D, Ueda T, Tezduyar TE (2016) A geometrical-characteristics study in patient-specific FSI analysis of blood flow in the thoracic aorta. In: Bazilevs Y, Takizawa K (eds) Advances in computational fluid-structure interaction and flow simulation: new methods and challenging computations, modeling and simulation in science, engineering and technology, Springer, pp 379-386. ISBN 978-3-319-408255. https://doi.org/10.1007/978-3-319-40827-9_29

116. Takizawa K, Tezduyar TE, Uchikawa H, Terahara T, Sasaki T, Shiozaki K, Yoshida A, Komiya K, Inoue G (2018) Aorta flow analysis and heart valve flow and structure analysis. In: Tezduyar TE (ed) Frontiers in computational fluid-structure interaction and flow simulation: research from lead investigators under forty-2018, modeling and simulation in science, engineering and technology, Springer, pp 29-89. ISBN 978-3-319-96468-3. https://doi.org/10.1007/978-3-319-96469-0_2

117. Takizawa K, Tezduyar TE, Uchikawa H, Terahara T, Sasaki T, Yoshida A (2019) Mesh refinement influence and cardiaccycle flow periodicity in aorta flow analysis with isogeometric discretization. Comput Fluids 179:790-798. https://doi.org/10. 1016/j.compfluid.2018.05.025

118. Takizawa K, Bazilevs Y, Tezduyar TE, Hsu M-C (2019) Computational cardiovascular flow analysis with the variational multiscale methods. J Adv Eng Comput 3:366-405. https://doi.org/10. 25073/jaec.201932.245

119. Takizawa K, Tezduyar TE (2016) New directions in spacetime computational methods. In: Bazilevs Y, Takizawa K (eds) Advances in computational fluid-structure interaction and flow simulation: new methods and challenging computations, modeling and simulation in science, engineering and technology, Springer, pp 159-178. ISBN 978-3-319-40825-5. https://doi.org/ 10.1007/978-3-319-40827-9_13

120. Yu Y, Zhang YJ, Takizawa K, Tezduyar TE, Sasaki T (2019) Anatomically realistic lumen motion representation in patientspecific space-time isogeometric flow analysis of coronary arteries with time-dependent medical-image data. Comput Mech. https://doi.org/10.1007/s00466-019-01774-4. https://doi.org/10. 1007/s00466-019-01774-4

121. Takizawa K, Montes D, McIntyre S, Tezduyar TE (2013) Spacetime VMS methods for modeling of incompressible flows at high Reynolds numbers. Math Models Methods Appl Sci 23:223-248. https://doi.org/10.1142/s0218202513400022

122. Takizawa K, Tezduyar TE, Hattori H (2017) Computational analysis of flow-driven string dynamics in turbomachinery. Comput Fluids 142:109-117. https://doi.org/10.1016/j.compfluid.2016. 02.019

123. Komiya K, Kanai T, Otoguro Y, Kaneko M, Hirota K, Zhang Y, Takizawa K, Tezduyar TE, Nohmi M, Tsuneda T, Kawai M, Isono M (2019) Computational analysis of flow-driven string dynamics in a pump and residence time calculation. In: IOP conference series earth and environmental science, vol 240, p 062014. https:// doi.org/10.1088/1755-1315/240/6/062014

124. Kanai T, Takizawa K, Tezduyar TE, Komiya K, Kaneko M, Hirota K, Nohmi M, Tsuneda T, Kawai M, Isono M (2019) Methods for computation of flow-driven string dynamics in a pump and residence time. Math Models Methods Appl Sci 29:839-870. https:// doi.org/10.1142/S021820251941001X

125. Otoguro Y, Takizawa K, Tezduyar TE (2017) Space-time VMS computational flow analysis with isogeometric discretization and a general-purpose NURBS mesh generation method. Comput Fluids 158:189-200. https://doi.org/10.1016/j.compfluid.2017. 04.017

126. Otoguro Y, Takizawa K, Tezduyar TE (2018) A general-purpose NURBS mesh generation method for complex geometries. In: Tezduyar TE (ed) Frontiers in computational fluid-structure interaction and flow simulation: research from lead investigators under forty -2018 , modeling and simulation in science, engineering and technology, Springer, pp 399-434. ISBN 978-3-319-964683. https://doi.org/10.1007/978-3-319-96469-0_10

127. Otoguro Y, Takizawa K, Tezduyar TE, Nagaoka K, Mei S (2019) Turbocharger turbine and exhaust manifold flow computation with the space-time variational multiscale method and isogeometric analysis. Comput Fluids 179:764-776. https://doi.org/10.1016/j. compfluid.2018.05.019

128. Otoguro Y, Takizawa K, Tezduyar TE, Nagaoka K, Avsar R, Zhang Y (2019) Space-time VMS flow analysis of a turbocharger turbine with isogeometric discretization: computations with time-dependent and steady-inflow representations of the intake/exhaust cycle. Comput Mech 64:1403-1419. https://doi. org/10.1007/s00466-019-01722-2

129. Kuraishi T, Takizawa K, Tezduyar TE (2018) Space-time computational analysis of tire aerodynamics with actual geometry, road contact and tire deformation. In: Tezduyar TE (ed) Frontiers in computational fluid-structure interaction and flow simulation: research from lead investigators under forty —2018, modeling 
and simulation in science, engineering and technology, Springer, pp 337-376. ISBN 978-3-319-96468-3. https://doi.org/10.1007/ 978-3-319-96469-0_8

130. Kuraishi T, Takizawa K, Tezduyar TE (2019) Tire aerodynamics with actual tire geometry, road contact and tire deformation. Comput Mech 63:1165-1185. https://doi.org/10.1007/s00466018-1642-1

131. Kuraishi T, Takizawa K, Tezduyar TE (2019) Space-time computational analysis of tire aerodynamics with actual geometry, road contact, tire deformation, road roughness and fluid film. Comput Mech 64:1699-1718. https://doi.org/10.1007/s00466019-01746-8

132. Kuraishi T, Takizawa K, Tezduyar TE (2019) Space-time Isogeometric flow analysis with built-in Reynolds-equation limit. Math Models Methods Appl Sci 29:871-904. https://doi.org/10.1142/ S0218202519410021

133. Takizawa K, Tezduyar TE, Terahara T (2016) Ram-air parachute structural and fluid mechanics computations with the space-time isogeometric analysis (ST-IGA). Comput Fluids 141:191-200. https://doi.org/10.1016/j.compfluid.2016.05.027

134. Takizawa K, Tezduyar TE, Kanai T (2017) Porosity models and computational methods for compressible-flow aerodynamics of parachutes with geometric porosity. Math Models Methods Appl Sci 27:771-806. https://doi.org/10.1142/S0218202517500166

135. Kanai T, Takizawa K, Tezduyar TE, Tanaka T, Hartmann A (2019) Compressible-flow geometric-porosity modeling and spacecraft parachute computation with isogeometric discretization. Comput Mech 63:301-321. https://doi.org/10.1007/s00466-018-1595-4

136. Hsu M-C, Bazilevs Y, Calo VM, Tezduyar TE, Hughes TJR (2010) Improving stability of stabilized and multiscale formulations in flow simulations at small time steps. Comput Methods Appl Mech Eng 199:828-840. https://doi.org/10.1016/j.cma.2009.06.019

137. Takizawa K, Tezduyar TE, Otoguro Y (2018) Stabilization and discontinuity-capturing parameters for space-time flow computations with finite element and isogeometric discretizations. Comput Mech 62:1169-1186. https://doi.org/10.1007/s00466-018-1557$\mathrm{x}$

138. Takizawa K, Ueda Y, Tezduyar TE (2019) A nodenumbering-invariant directional length scale for simplex elements. Math Models Methods Appl Sci. https://doi.org/10.1142/ S0218202519500581

139. Otoguro Y, Takizawa K, Tezduyar TE (2019) Element length calculation in B-spline meshes for complex geometries. Comput Mech. https://doi.org/10.1007/s00466-019-01809-w

140. Corsini A, Menichini C, Rispoli F, Santoriello A, Tezduyar TE (2009) A multiscale finite element formulation with discontinuity capturing for turbulence models with dominant reactionlike terms. J Appl Mech 76:021211. https://doi.org/10.1115/1.3062967

141. Rispoli F, Saavedra R, Menichini F, Tezduyar TE (2009) Computation of inviscid supersonic flows around cylinders and spheres with the V-SGS stabilization and YZ $\beta$ shock-capturing. J Appl Mech 76:021209. https://doi.org/10.1115/1.3057496

142. Corsini A, Iossa C, Rispoli F, Tezduyar TE (2010) A DRD finite element formulation for computing turbulent reacting flows in gas turbine combustors. Comput Mech 46:159-167. https://doi.org/ 10.1007/s00466-009-0441-0

143. Corsini A, Rispoli F, Tezduyar TE (2011) Stabilized finite element computation of NOx emission in aero-engine combustors. Int $\mathrm{J}$ Numer Methods Fluids 65:254-270. https://doi.org/10.1002/fld. 2451

144. Corsini A, Rispoli F, Tezduyar TE (2012) Computer modeling of wave-energy air turbines with the SUPG/PSPG formulation and discontinuity-capturing technique. J Appl Mech 79:010910. https://doi.org/10.1115/1.4005060

145. Corsini A, Rispoli F, Sheard AG, Tezduyar TE (2012) Computational analysis of noise reduction devices in axial fans with stabilized finite element formulations. Comput Mech 50:695-705. https://doi.org/10.1007/s00466-012-0789-4

146. Kler PA, Dalcin LD, Paz RR, Tezduyar TE (2013) SUPG and discontinuity-capturing methods for coupled fluid mechanics and electrochemical transport problems. Comput Mech 51:171-185. https://doi.org/10.1007/s00466-012-0712-z

147. Corsini A, Rispoli F, Sheard AG, Takizawa K, Tezduyar TE, Venturini P (2014) A variational multiscale method for particle-cloud tracking in turbomachinery flows. Comput Mech 54:1191-1202. https://doi.org/10.1007/s00466-014-1050-0

148. Rispoli F, Delibra G, Venturini P, Corsini A, Saavedra R, Tezduyar TE (2015) Particle tracking and particle-shock interaction in compressible-flow computations with the V-SGS stabilization and $\mathrm{YZ} \beta$ shock-capturing. Comput Mech 55:1201-1209. https:// doi.org/10.1007/s00466-015-1160-3

149. Cardillo L, Corsini A, Delibra G, Rispoli F, Tezduyar TE (2016) Flow analysis of a wave-energy air turbine with the SUPG/PSPG stabilization and discontinuity-capturing directional dissipation. Comput Fluids 141:184-190. https://doi.org/ 10.1016/j.compfluid.2016.07.011

150. Castorrini A, Corsini A, Rispoli F, Venturini P, Takizawa K, Tezduyar TE (2016) Computational analysis of wind-turbine blade rain erosion. Comput Fluids 141:175-183. https://doi.org/10. 1016/j.compfluid.2016.08.013

151. Castorrini A, Corsini A, Rispoli F, Venturini P, Takizawa K, Tezduyar TE (2019) Computational analysis of performance deterioration of a wind turbine blade strip subjected to environmental erosion. Comput Mech 64:1133-1153. https://doi.org/10.1007/ s00466-019-01697-0

152. Tezduyar TE, Aliabadi SK, Behr M, Mittal S (1994) Massively parallel finite element simulation of compressible and incompressible flows. Comput Methods Appl Mech Eng 119:157-177. https://doi.org/10.1016/0045-7825(94)00082-4

153. Hughes TJR, Cottrell JA, Bazilevs Y (2005) Isogeometric analysis: CAD, finite elements, NURBS, exact geometry, and mesh refinement. Comput Methods Appl Mech Eng 194:4135-4195

154. Takizawa K, Tezduyar TE (2014) Space-time computation techniques with continuous representation in time (ST-C). Comput Mech 53:91-99. https://doi.org/10.1007/s00466-013-0895-y

155. Takizawa K, Takagi H, Tezduyar TE, Torii R (2014) Estimation of element-based zero-stress state for arterial FSI computations. Comput Mech 54:895-910. https://doi.org/10.1007/s00466-0130919-7

156. Takizawa K, Torii R, Takagi H, Tezduyar TE, Xu XY (2014) Coronary arterial dynamics computation with medical-image-based time-dependent anatomical models and element-based zero-stress state estimates. Comput Mech 54:1047-1053. https://doi.org/10. 1007/s00466-014-1049-6

157. Takizawa K, Tezduyar TE, Sasaki T (2018) Estimation of elementbased zero-stress state in arterial FSI computations with isogeometric wall discretization. In: Wriggers P, Lenarz T (eds) Biomedical technology: modeling, experiments and simulation, Lecture notes in applied and computational mechanics, Springer, pp 101-122. ISBN 978-3-319-59547-4. https://doi.org/10.1007/ 978-3-319-59548-1_7

158. Takizawa K, Tezduyar TE, Sasaki T (2017) Aorta modeling with the element-based zero-stress state and isogeometric discretization. Comput Mech 59:265-280. https://doi.org/10.1007/s00466016-1344-5

159. Sasaki T, Takizawa K, Tezduyar TE (2019) Aorta zero-stress state modeling with T-spline discretization. Comput Mech 63:13151331. https://doi.org/10.1007/s00466-018-1651-0

160. Sasaki T, Takizawa K, Tezduyar TE (2019) Medical-image-based aorta modeling with zero-stress-state estimation. Comput Mech 64:249-271. https://doi.org/10.1007/s00466-019-01669-4 
161. Takizawa K, Tezduyar TE, Sasaki T (2019) Isogeometric hyperelastic shell analysis with out-of-plane deformation mapping. Comput Mech 63:681-700. https://doi.org/10.1007/s00466-0181616-3

162. Stein K, Tezduyar T, Benney R (2003) Mesh moving techniques for fluid-structure interactions with large displacements. J Appl Mech 70:58-63. https://doi.org/10.1115/1.1530635
Publisher's Note Springer Nature remains neutral with regard to jurisdictional claims in published maps and institutional affiliations. 